Elzahar, H., Hussainey, K., Mazzi, F., and Tsalavoutas, I. (2015) Economic consequences of key performance indicators' disclosure quality. International Review of Financial Analysis, 39, pp. 96-112.

Copyright $@ 2015$ Elsevier Inc.

A copy can be downloaded for personal non-commercial research or study, without prior permission or charge

Content must not be changed in any way or reproduced in any format or medium without the formal permission of the copyright holder(s)

When referring to this work, full bibliographic details must be given

http://eprints.gla.ac.uk/103757/

Deposited on: 28 May 2015

Enlighten - Research publications by members of the University of Glasgow http://eprints.gla.ac.uk 


\title{
Economic consequences of Key Performance Indicators' disclosure quality
}

\author{
Hany Elzahar (Damietta University) \\ Khaled Hussainey (University of Plymouth) \\ Francesco Mazzi (University of Florence) \\ Ioannis Tsalavoutas* (University of Glasgow)
}

\section{ACKNOWLEDGMENTS}

We thank the Accounting and Finance division at the University of Stirling, Damietta University and the Ministry of higher education in Egypt for funding this study. We also gratefully acknowledge helpful comments received from two anonymous reviewers, Basil Al-Najjar, Dionysia Dionysiou, Ian Fraser, Alan Goodacre, Patrick Herbst, Brian Singleton-Green, Richard Slack, the participants of the $16^{\text {th }}$ FRBC Conference (Bristol, July 2012), of the research seminar at the Accounting and Finance division at the University of Stirling (Stirling, November 2012), of the 36th Annual Congress of the EAA (Paris, May, 2013), of SWAG BAFA conference (Gloucester, September, 2013), of the 50th BAFA Annual Congress (London, April, 2014), of the 37th Annual Congress of the EAA (Tallinn, May, 2014), and of the 5th Financial Reporting Workshop (Verona, June, 2014).

\section{Correspondence Details}

*Correspondence should be addressed to Dr Ioannis Tsalavoutas, University of Glasgow, Adam Smith Business School, West Quadrangle, Main Building, Room G683, University Avenue, Glasgow, G12 8QQ, Scotland, UK. E-mail: Ioannis.Tsalavoutas@glasgow.ac.uk. 


\title{
Economic consequences of Key Performance Indicators' disclosure quality
}

\begin{abstract}
Starting from 2006, UK listed companies are required to analyse their performance by using Key Performance Indicators (KPIs) in specific sections of their annual reports and the UK Accounting Standard Board (ASB) provides companies with guidelines for the best practice regarding KPI disclosure. Motivated by the possible effects of the KPI disclosure quality, we examine their potential economic consequences for a sample of UK listed firms for the period 2006 to 2010. Our sample consists of 448 firm-year observations. We first develop a measure for the quality of the KPI disclosure based on the ASB's guidelines. We then test the economic consequences of financial and nonfinancial KPIs disclosure quality both separately and combined into one variable. Our findings, after conducting various sensitivity tests, suggest that only the disclosure quality of financial KPIs matters. We find a significantly negative (weakly positive) relationship between disclosure quality of financial KPIs and the implied cost of capital (firm value). These results inform regulatory bodies as well as the academic literature about the potential economic consequences of this type of disclosure.
\end{abstract}

Keywords: KPIs disclosure quality, Cost of capital, Value relevance, UK.

JEL Classifications: M40, M41, M48, G10. 


\section{Introduction}

The UK Companies Act (CA) of 2006 defines key performance indicators (KPIs) as the 'factors by reference to which the development, performance or position of the business of the company can be measured effectively' (UK Companies Act (CA), 2006: 196). The reporting of KPIs should be valuable for investors because they contain information related to important aspects of companies' activities which might not be clearly reflected in the financial statements (ACIFR, 2008). Therefore, KPIs disclosure is crucial in supporting companies' communication with stakeholders in order to enable a better understanding of financial statements and the companies' progress towards the achievement of their objectives and targets (Accounting Standard Board (ASB), 2006).

Many regulatory bodies suggest or require companies to disclose KPIs within their annual reports (e.g., EU Accounts Modernisation Directive, 2003; IASB, 2010; and SEC, 2003). ${ }^{1}$ In the UK in particular, section 417 of the CA (2006) introduced the requirement for companies (except the small ones) to analyse their performance by using KPIs in their Business Review. ${ }^{2}$ These could be financial or, 'if appropriate', nonfinancial. The latter could include environmental and employee matters (CA, 2006). Furthermore, in January 2006, the ASB issued the reporting statement 'Operating and Financial Review' (OFR) which contains guidelines for the best practices regarding KPI disclosure. However, the nature of these requirements allows companies' directors to exercise discretion on the reporting of KPIs: a) they can determine the extent necessary for financial and nonfinancial KPIs for an understanding of the development, performance, or position of the company; b) they can determine what is appropriate when reporting nonfinancial KPIs; and c) they can take advantage of the exemption provisions (10, 11 section 417 of CA, 2006) for not providing KPIs information because of confidentiality reasons. Therefore, the quality and quantity of KPI reporting should vary among UK companies. However, many reports (e.g., FRC, 2007; 2009) and

\footnotetext{
${ }^{1}$ Throughout the study, EU stands for European Union, SEC stands for Securities and Exchange Commission, and IASB stands for International Accounting Standards Board.

${ }^{2}$ In 2013, this requirement was repealed by SI 2013/1970 and superseded by Strategic Report requirements. Thus, the substance of the requirement remains.
} 
regulatory bodies (IASB, 2010; SEC, 2003) highlight that quality is the crucial issue in KPIs reporting and raise concerns about the usefulness of quantity of information regarding KPIs.

Despite these concerns, we identify only a research monograph which investigates the quantity or the quality of KPI reporting for a small sample of UK listed companies. ${ }^{3}$ Further, we know of no study which examines the economic consequences of these disclosures in the UK. ${ }^{4}$ Considering this gap in the literature, we first develop a research instrument to measure the quality of the KPIs disclosure. This instrument considers the qualitative attributes of KPIs information as suggested by the OFR (ASB, 2006) which are expected to be fulfilled by companies' corresponding disclosure. Subsequently, we manually collect our data from the annual reports of a randomly selected sample of UK nonfinancial firms which were constituents of the FTSE 350 for the five-year period of 2006 to 2010 that results in 448 observations. Once we calculate KPIs disclosure scores, we conduct univariate and multivariate analyses to explore their relationship with companies’ implied cost of capital (ICC) and their value relevance.

We find high variations in KPIs reporting practice across the sample firms with a clear tendency to focus on financial KPIs. Although the quality of KPIs disclosure increases over time, the mean quality scores are relatively low (below 50\% for both financial and nonfinancial KPIs). These low scores indicate that although the companies do disclose some information about financial and nonfinancial KPIs, they fail to follow the ASB's (2006) guidelines for best practice. Our empirical results show that the quality of financial KPI disclosures is negatively related with companies’ ICCs and has a weakly positive relationship with their market values. Additional tests also show that the quantity of KPIs reporting results in no economic consequences, which confirms the regulatory bodies’ recommendations that the quality of KPI reporting is of great importance.

\footnotetext{
${ }^{3}$ Tauringana and Mangena (2009) investigate the reporting of KPIs by 32 UK media sector companies listed on the London Stock Exchange over the period 2004 to 2007.

${ }^{4}$ In fact, to the best of our knowledge, the only study focusing on KPIs reporting being relevant to this one, to some extent, is the study by Dorestani and Rezaee (2011). The authors examine the association between non-financial KPIs disclosures and the accuracy of analysts' forecasts for a sample of US firms for the two-year period 2006 and 2007.
} 
Based on these findings, our study contributes to the literature in several ways. First, we develop a context-specific measure of the quality of KPIs reporting. As highlighted by Leuz and Wysocki (2008), there is a lack of a measure which combines all of the desirable properties for disclosure. The approach we follow could be beneficial for future studies dealing with disclosures in order to avoid proxy-selection biases. Second, we add empirical evidence about the economic consequences of the quality of the KPIs disclosure. We find that the more companies disclose financial KPIs that follow the ASB's (2006) guidelines, the more they benefit from a reduction in their cost of capital and an increase in their market value. These results suggest that KPIs related information in companies' annual reports is fed into the companies' cost of capital and market valuation, indicating that the requirement for companies to disclose KPIs contains value relevant information for financial statements users. This should be of interest to companies as well as regulators. Additionally, our findings of very low quality levels for KPIs disclosure indicate that many UK firms do not follow the ASB's corresponding guidelines and this should have an appeal to regulators. Arguably, more consultation with preparers and users on how the principles to be followed could add value by improving the quality of the information disclosed. Finally, this study has policy implications beyond the EU and the UK in particular. It is also relevant in the US since the SEC has introduced the requirement for companies to publish KPIs since 2003 and research regarding the economic consequences of such reporting is absent.

The remainder of the paper is organised as follows. Section 2 draws on the relevant regulatory framework and has a review of the relevant literature. In this section, we also develop the hypotheses tested. Section 3 discusses the research design. Section 4 presents the empirical analysis, and Section 5 discusses the results from the sensitivity tests. Section 6 concludes. 


\section{Regulatory Framework and Hypotheses Development}

\subsection{Regulatory framework}

To highlight the increasing trend of requiring KPIs reporting across the world and in the UK in particular, this section reports the main relevant requirements for KPIs reporting that came into force the last decade or so. At an international level, first, in 2003, the SEC released a guideline which emphasises that 'companies should identify and discuss key performance indicators, including nonfinancial performance indicators, that their management uses to manage the business and that would be material to investors' (SEC, 2003). Also in 2003, the EU adopted the Accounts Modernisation Directive (2003) according to which the companies in Member States are required to include in their annual reports 'both financial and, where appropriate, nonfinancial key performance indicators relevant to the particular business, including information relating to environmental and employee matters' (EU Accounts Modernisation Directive, 2003). And, in 2010, the IASB issued a practice statement entitled Management Commentary according to which companies preparing their financial statements under the International Financial Reporting Standards (IFRS) are required to disclose in the Management Commentary the 'performance measures and indicators (both financial and nonfinancial) that are used by management to assess progress against its stated objectives.' (IASB, 2010: 15).

In the UK, while implementing the aforementioned EU Directive, the CA (2006) (Section 417) required all companies, except those defined as 'small', to analyse their performance using KPIs in the Business Review. ${ }^{5}$ The act states that KPIs could be financial or, if appropriate, nonfinancial, that cover, for example, environmental and employee matters. However, the nature of the regulation enables companies' directors to control KPI reporting at least in the following ways: a) by determining the 'extent necessary' (CA, 2006: 196) for financial KPI reporting; b) by judging when the nonfinancial KPI reporting is ‘appropriate’ (ibid: 196) ; and c) by avoiding KPI reporting 'if the disclosure would, in the opinion of the directors, be seriously prejudicial to the interests of the

\footnotetext{
${ }^{5}$ In 2013, this requirement was repealed by SI 2013/1970 and superseded by Strategic Report requirements. Thus, the substance of the requirement remains.
} 
company' (ibid: 197). Additionally, the CA (2006) does not have a sample set of KPIs to be reported by all companies nor a specific guideline on how to present KPIs. ${ }^{6}$ Therefore, KPIs related disclosure is considered quasi voluntary instead of mandatory.

This discretion led the ASB to issue the reporting statement 'OFR' in 2006. This contains guidelines to achieve the best practices regarding the KPIs disclosure, although it does not provide a specific list of KPIs to be reported. It concentrates on KPIs reporting practice and lists qualitative key characteristics to be fulfilled when companies report KPIs. Moreover, with a focus only on nonfinancial KPIs, the Department for Environment, Food and Rural Affairs (DEFRA) issued guidelines on how UK companies should measure and report on their environmental impacts (DEFRA, 2006; 2012).

Surprisingly, there is absence of academic research which explores the potential economic consequences and valuation implications of KPIs disclosure. Focusing on the UK, the Financial Reporting Council (FRC) has repeatedly monitored KPI reporting practices and has highlighted many critical points mainly in terms of the quality of KPIs reporting. First, a report issued by the FRC in 2007 reflects on the KPIs reporting practice by UK listed companies in 2006. The report concludes that 'many companies are providing a good deal of information on measures and indicators, but improvements can be made in identifying their KPIs, both financial and nonfinancial' (FRC, 2007: 3). A similar report was issued by the FRC in 2009. This reviewed the narrative reporting by UK listed companies in 2008 and 2009 and points out that some companies were not disclosing KPIs. Thus, the report suggests that the CA's (2006) wording 'to the extent necessary' and 'where appropriate' provided excuses for avoiding the KPIs disclosure, even though the KPIs can always enhance the narrative (FRC, 2009). Conversely, other companies were reporting too many KPIs: in some cases 'there were too many KPIs to all be key - for example, one company listed 68 measures throughout the report and there were several others with close to 20' (FRC, 2009: 27). Therefore, similar to the earlier report, the FRC (2009) has focused on best

\footnotetext{
${ }^{6}$ The same applies to SEC (2003), EU Accounts Modernisation Directive (2003), and IASB (2010).
} 
practices for KPIs reporting in terms of quality and has stated that quality can be achieved when 'each KPI disclosure includes definition, purpose, comparatives, commentary on targets, etc.' (FRC, 2009: 26). This report does not contain a list of KPIs to be disclosed, but preparers are advised to report only those KPIs which are clearly relevant to the business. The findings of both reports and the guidelines from the ASB (2006) and DEFRA (2006; 2012) indicate that what matters in KPIs reporting is quality and not quantity. The same conclusion appears to be the focus for the SEC (2003) and the IASB (2010) guidelines given that they both suggest that the KPIs reported should be accompanied by information which enhances their understanding and why they are relevant.

The focus on KPIs reporting quality is understandable, if one considers that information conveyed through this type of disclosure is not standardised (as it would be if mandated by accounting standards for example). Thus, a clear indication of the KPIs' qualitative characteristics (e.g., definition, calculation method, purpose for disclosing, and motivation of why the disclosure should be useful to users of the annual report) is essential for the understanding of the nature of a firm's business and value creation model. These characteristics are included in those highlighted by the ASB (2006). Considering the definition of KPIs in the CA (2006) and the important expectations about the usefulness and relevance of this type of disclosure, we develop a measure which captures the KPIs disclosure quality and investigate their economic consequences. We examine the relationship of KPIs reporting quality with the cost of capital and market value of UK firms.

\subsection{Hypotheses Development}

Given that KPIs reporting intends to provide investors with a better understanding of the data contained in financial statements and is available to the insiders (CA, 2006; FRC, 2007; 2009; IASB, 2010; SEC, 2003), KPIs disclosure should mitigate problems from information asymmetry. Financial and nonfinancial KPIs should reduce the uncertainty with regard to business performance, 
therefore helping investors to make a better valuation of a company. In such contexts, the disclosure literature argues that corporate disclosure is able to reduce the information asymmetry between insiders and outsiders (e.g., Kothari et al., 2009). Thus, enhanced disclosure might lead to an increase in the demand for a company's share and in turn the share's price (Clarkson et al., 1996; Hassan et al., 2009) because the disclosure should correct any firm misevaluation (Healy et al., 1999). A rich information environment could lead to desirable economic consequences such as a reduction in the firm's cost of equity capital (Beyer et al., 2010; Leuz and Wysocki, 2008) and an increase in the firm's value (Leuz and Wysocki, 2008).

The disclosure literature offers two theoretical frameworks to support the proposition that greater corporate disclosure is associated with a lower cost of capital. The first suggests that disclosure reduces adverse selection and, as a result, increases liquidity. As discussed above, greater disclosure reduces the possibility of information asymmetries. This, in turn, enhances stock liquidity and reduces the cost of capital by reducing the discount at which shares are sold through reduced transaction costs or by increasing the demand for a firm's securities (e.g., Diamond and Verrecchia, 1991; Easley and O’Hara, 2004). The second framework suggests that increased disclosure reduces the estimation risk in two ways: first, securities with more information are less risky because of lower uncertainty surrounding the exact parameters of their return distribution (e.g., Clarkson et al., 1996; Easley and O’Hara, 2004); and, second, the covariance of a firm’s cash flow with the cash flow of other firms decreases as disclosures increase (e.g., Hughes et al., 2007; Lambert et al., 2007). Thus, enhanced corporate disclosure directly reduces estimation risk that leads to an indirect reduction in the firm's cost of capital.

The latter framework is also useful in examining the link between corporate disclosure and firm value. In addition to the direct effects on the covariance of a firm's cash flow, corporate disclosures have the potential to change the firm value by affecting managers' decisions and hence altering the distribution of future cash flows (Lambert et al., 2007). Thus, there might be indirect effects on the firm value through cash flow expectations formed on the basis of enhanced corporate disclosure. 
Based on these findings, improved corporate disclosure should reduce the cost of capital and increase the market value at the same time. However, the firm value might change even if the cost of capital does not. This change in value happens when cash flow expectations do not change proportionally to covariance estimates (Pope and McLeay, 2011). Thus, in exploring the economic consequences of KPIs reporting, we focus both the cost of capital and the firm value.

The empirical evidence for the effect of disclosure on companies' cost of capital and their market value is mixed (Beyer et al., 2010; Kothari et al., 2009; Healy and Palepu, 2001). For example, some studies report a negative association between disclosure levels and firms' cost of equity capital (e.g., Botosan 1997; Richardson and Welker, 2001; Hail, 2002). However, Botosan and Plumlee (2002) find a negative (positive) association between annual report disclosures (quarterly report disclosures) and the cost of capital.

Similarly, the empirical literature examining the link between corporate disclosure and firm value also offers mixed results. For example, a number of studies report a positive association between these two variables (e.g. Baek et al., 2004; Cheung et al., 2010; Jiao, 2011). However, Hassan et al. (2009) find that there is no significant association between firm value and voluntary disclosure, while there is a negative and significant relation with mandatory disclosure when the relation of their relationship with market value is tested simultaneously. Finally, Uyar and Kiliç (2012) find that the association between voluntary disclosure and firm value varies depending on the proxy used for firm value.

Beattie et al. (2004) suggest that the mixed evidence on the economic consequences of enhanced disclosure might be due to an insufficient degree of accuracy in measuring the primary variable of interest (i.e., disclosure). Along these lines, Leuz and Wysocki (2008) argue that the theoretical research provides little guidance on what form of disclosure is relevant for various stakeholders. They also underline that many desirable properties of corporate disclosures have been identified so far: for example quantity, quality, timeliness, relevance, reliability, and comparability. However, some of these are in conflict with others. Thus, Beyer et al. (2010) argue that there is a 
lack of a definition of voluntary disclosure and financial reporting quality and recommend that future research addresses this issue. In spite of this call, researchers are still facing the challenge of identifying and capturing the most important dimensions of high quality corporate information (Leuz and Wysocki, 2008).

The KPIs reporting in the UK offers a unique setting to contribute to the disclosure literature. However, one caveat is that the KPIs disclosure can be considered as quasi voluntary because a high degree of discretion is left to managers despite its requirement by CA (2006). Thus, we test the following non-directional hypotheses: ${ }^{7}$

H1: KPIs disclosure quality is significantly associated with the cost of equity capital.

H2: KPIs disclosure quality is value relevant.

Additionally, because the CA (2006) requires directors to disclose financial KPIs and, if appropriate, nonfinancial KPIs and the different nature of these two sets of information, we also test the following ancillary hypotheses:

H1.a: Financial KPIs disclosure quality is significantly associated with the cost of equity capital.

H1.b: Nonfinancial KPIs disclosure quality is significantly associated with the cost of equity capital.

H2.a: Financial KPIs disclosure quality is value relevant.

H2.b: Nonfinancial KPIs disclosure quality is value relevant.

\section{Research design}

\subsection{Measurement of KPIs disclosure quality}

To derive our measure of KPIs disclosure quality, we draw on the OFR (2006) guidelines. These describe the key qualitative characteristics of each KPI (see Appendix A for a full list of the

\footnotetext{
${ }^{7}$ Reflecting on Leuz and Wisocki's (2008: 24) proposition that 'theoretical research provides little guidance on what form, quantity and frequency of disclosure is relevant for various stakeholders', we also test the economic consequences of KPIs disclosure quantity as a sensitivity test (see Section 5).
} 
characteristics). We consider that if KPIs disclosure meet these characteristics, then the reporting should be of high quality. The following example is indicative of the usefulness of our measure. Drawing on the annual report published by Qinetic Group PLC in 2007, we find seven financial and two nonfinancial KPIs: proportion of revenue generated in North America; book to bill ratio; backlog; underlying earnings per share growth; total shareholder return; operating cash conversion; underlying operating profit margin; health and safety of employees; and staff attrition rate. While the meaning and usefulness of some of the above KPIs is easily understandable because of their link to information related to the financial statements, a broad discussion is needed in order to achieve a full comprehension of the information that some of these KPIs convey, including why they are considered relevant to the shareholders (e.g., book to bill ratio; backlog, staff attrition rate). In line with the FRC (2009), disclosing the information suggested by the guidelines should indicate the quality of the KPI reporting. Thus, our measure considers the content of the KPI disclosure that should enhance the understanding of the discussion and analysis.

Based on this, a dichotomous scoring approach is applied by manually capturing each KPI's disclosure quality. If a required quality dimension is met, it is scored as one, otherwise it is scored as zero. If a quality dimension is not applicable to a specific KPI, then it is scored as 'not applicable’ (NA) (e.g. Cooke, 1992). ${ }^{8}$ Following this procedure, the quality score for each KPI is calculated as a ratio of the total quality dimensions at the maximum quality score achievable for that specific KPI (time subscripts omitted):

$$
\operatorname{QlAvKPIs}_{k, j}=\frac{T_{k, j}=\sum_{i=i_{1, k, j}}^{i_{n, k, j}} d_{i, k, j}}{M_{k, j}=\sum_{i=i_{1, k, j}}^{i_{m, k, j}} d_{i, k, j}}
$$

where $T_{k, j}$ is the total number of quality dimensions $\left(d_{i}, 0 \leq i \leq n\right)$ observed for KPI $k$ by firm $j$, and $M_{k, j}$ is the maximum number of applicable quality dimensions $\left(d_{i}, 0 \leq i \leq m, m \geq n\right)$ for KPI

\footnotetext{
${ }^{8}$ For example, one of the desirable characteristics of KPIs reported is to show adjustments to any financial statement information used. However, this characteristic might not be applicable to some nonfinancial KPIs.
} 
$k$ by firm $j .^{9}$

Once each KPI’s disclosure quality is measured, we estimate each firm-year observation's overall KPI disclosure quality. This is derived as the mean of the KPI quality scores. Thus, KPIs disclosure quality for each firm is weighted by the number (i.e., quantity) of KPIs reported. This weight is presented as follows (time subscripts omitted):

$$
Q l A v K P I s_{j}=\frac{\sum_{k=k_{1, j}}^{k_{n, j}} Q l A v K P I s_{k, j}}{k_{n, j}}
$$

where $Q l A v K P I s_{j}$ is the KPI quality score for firm $j$, lying between zero and one; $Q l A v K P I s_{k, j}$ is each KPI quality score measured according to Eq. (1); and $k_{n, j}$ is the number of KPIs disclosed by firm $j$. When no KPI is disclosed, $Q l A v K P I s_{j}$ is equal to zero. This value means that firm $j$ conveys no relevant information with regard to any of the qualitative characteristics in the OFR.

We apply this method to derive six scores of KPIs disclosure quality: the overall quality scores disclosed in the annual report (OvKPIsRep) or just in the Business Review (OvKPIsSec); the scores related to the financial KPIs only disclosed in the annual report (FKPIsRep) or just in the Business Review (FKPIsSec); the scores related to the nonfinancial KPIs only disclosed in the annual report (NonFKPIsRep) or just in the Business Review (NonFKPIsSec). Appendix B provides an example of how we compute overall quantity and quality of KPIs reporting as well as for financial and nonfinancial KPIs separately. ${ }^{10}$

We do not use the actual QIAvKPIs scores in the multivariate analysis. We employ the following transformations instead. First, we calculate the percentile rank (QIAvKPIs_rank) (e.g., Glaum et al., 2013; Nikolaev and Van Lent, 2005) by using the dense rankings in the following

\footnotetext{
${ }^{9}$ Quality dimensions are unweighted in order to avoid subjectivity in selecting a set of weights, given the lack of a commonly accepted procedure in the disclosure literature.

${ }^{10}$ Before scoring all of our sample firms, we conduct a pilot study on a randomly selected sample of ten annual reports to address the validity and reliability of our instrument (cf., Tsalavoutas et al., 2010). We first develop decision rules, and these are used as a reference while coding. Furthermore, each researcher independently codes the annual reports of the pilot study sample to ensure consistency in applying these rules. Additionally, we perform nonparametric tests (Kruskal-Wallis) to compare the quality scores we coded separately. These indicate that there is no significant difference between the median scores among us, verifying the reliability of our research instrument (results are available upon request). While following this process we noticed that companies do not disclose KPIs only in the Business Review as suggested by the CA (2006), but also in other areas of the annual report.
} 
equation:

$$
\text { QlAvKPIs_rank }_{j, t}=\frac{\text { Rank }_{j, t}-1}{\text { MaxDense }_{t}-1}
$$

where $Q l A v K P I s_{-} r a n k_{j, t}$ is the percentile rank of firm $j$ during year $t, R_{a n k_{j, t}}$ is the rank/position of firm $j$ during year $t$, and MaxDense $e_{t}$ is the sample size less the number of ties for year $t$. The KPIs disclosure quality is ranked in ascending order, so that the newly created variable increases with the KPIs disclosure quality (see, e.g., Glaum et al., 2013; Hail, 2002) and this variable lies between zero and one. ${ }^{11}$ Thus, according to our hypotheses, the higher (lower) the KPIs disclosure quality, then the lower (higher) the cost of capital and the higher (lower) the KPIs disclosure quality's value relevance. Second, we also consider the normal scores (QIAvKPIs_norm) as an alternative transformation (Cooke, 1998). We calculate QLAvKPIs_norm by using the following equation:

$$
\operatorname{QlAvKPIS}_{\text {rank }_{j, t}}=\varphi^{-1}\left(\frac{\text { Rank }_{j, t}}{\text { MaxDense }_{t}+1}\right)
$$

where $Q l A v K P I s_{-}$norm $_{j, t}$ is the normal score of firm $j$ during year $t$, and $\varphi^{-1}(\cdot)$ is the inverse of the cumulative density normal function.

\subsection{Cost of equity measurement}

Early studies on estimating cost of equity capital relied on ex-post realised returns to measure the ex-ante expected returns. However, subsequent studies demonstrate that realised returns are a noisy proxy for expected returns (e.g., Fama and French, 2002). Among all of the possibilities, we focus on the implied cost of equity capital (hereafter, ICC) that does not rely on biased realised returns or on asset pricing models (Hou et al., 2012) because its reasoning is based on a variation of the Edwards-Bell-Ohlson accounting model (Edwards and Bell, 1961; Ohlson, 1995).

During the last decade, many ICC models have been developed and compared in the literature.

\footnotetext{
${ }^{11}$ For example, for 2009, we identify the following levels of quality of Financial KPIs reporting for companies A, B and $\mathrm{C}$ in our sample: $0.15,0.40$, and 0.625 . Their corresponding percentile rakings are $0.015,0.367$, and 0.953 .
} 
Botosan and Plumlee (2005) compare five measure of the ICC and demonstrate that the one proposed in Botosan and Plumlee (2002) (hereafter, $r_{D I V}$ ) and in Easton (2004) (hereafter, $r_{P E G}$ ) are the most reliable. This conclusion is inferred from the fact that $r_{D I V}$ and $r_{P E G}$ are consistently and predictably related to corporate characteristics such as market risk, leverage risk, information risk, residual risk, and growth. Easton and Monahan (2005) compare seven ICC measures (including $r_{P E G}$ but not $r_{D I V}$ ) and conclude that all are unreliable proxies. However, they argue that the measure developed by Claus and Thomas (2001) (hereafter, $r_{C T}$ ) is a reliable proxy for firms with low consensus long-term growth forecasts. In recent years, Botosan et al. (2011) test the validity and reliability of eleven proxies for the ICC. In line with Botosan and Plumlee (2005), they again conclude that $r_{D I V}$ and $r_{P E G}$ are the most valid and reliable proxies. Considering the findings of these studies, it can be concluded that the ICC literature has not yet identified a commonly agreed method for estimating the ICC.

Moreover, as highlighted in Mazzi et al. (2014), the above said comparisons are based on US data and they sometimes rely on US databases (e.g. Value Line). The EU analyses commonly use data available in I/B/E/S (e.g., Kim et al., 2012; Li, 2010) and are therefore not able to estimate some ICC measures compared in the previous cited studies (e.g., $r_{D I V}$ ). As a result, in order to avoid or mitigate some biases highlighted in the literature, many empirical studies have used an average of various ICC models (e.g., Daske et al., 2008; Hail and Leuz, 2006). Similarly, we use the average of four different measures of the ICC (hereafter $r_{A V}$ ), which are the models used by Claus and Thomas (2001) (hereafter $r_{C T}$ ), Gebhardt et al. (2001) (hereafter $r_{G L S}$ ), Gode and Mohanran (2003) (hereafter $r_{G M}$ ), and Easton (2004) (hereafter $r_{M P E G}$ ). An indirect advantage of using $r_{A V}$ is that it allows us to discard as few as possible observations from our sample due to data unavailability. ${ }^{12}$

\footnotetext{
${ }^{12}$ We have used the same models' properties and the details used in their estimation as in Mazzi et al., (2014). Refer to the informative appendices B \& C in Mazzi et al., (2014) for a description of these details.
} 


\subsection{Multivariate analyses}

To test our first set of hypotheses (H1, H1.a and H1.b), we proceed as follows. We consider that the ICC is a function of KPIs disclosure quality and other control factors suggested by prior empirical literature. The latter include risk, growth, and size (e.g., Daske et al., 2008; Li, 2010). Thus, we estimate the following regression model:

$$
r_{i, t}=\beta_{0}+\beta_{1} Q \operatorname{lAvKPIs_{i,t}}+\beta_{2} \sum \text { controls }_{i, t}+\varepsilon_{i, t}
$$

where $r$ is the implied cost of capital based on the mean of the four estimated ICC measures described above. The controls are the $M 2 B$ (market value (WC08001) to book value of equity (WC03501)), SalG (percentage change in sales (WC01001)), AWCA (absolute value of abnormal working capital accruals scaled by total assets, according to Marra et al., 2011), ${ }^{13}$ rVar (return variance over the financial year, $\ln \left(R I_{t_{-11}} / R I_{t_{0}}\right)$ ); Dispersion (EPS forecasts standard deviation, STDEV in $\mathrm{I} / \mathrm{B} / \mathrm{E} / \mathrm{S}$ ), and AnFollow (the number of analysts following the firm, NUMEST in $\mathrm{I} / \mathrm{B} / \mathrm{E} / \mathrm{S})$.

To test our second set of hypotheses (i.e., H2, H2.a and H2.b), we use Ohlson’s (1995) model as a framework which combines accounting and non-accounting data. This method allows us to treat the KPIs disclosure quality as 'other information' available to the market participants. Consistent with this approach, we estimate the following regression model:

$$
M V_{i, t}=\beta_{0}+\beta_{1} B V_{i, t}+\beta_{2} N I_{i, t}+\beta_{3} Q l A v K P I s_{i, t}+\varepsilon_{i, t}
$$

where $M V$ is the market value of equity (WC08001), $B V$ is the book value of equity (WC03501), and NI is the net income (WC01751). All of these variables are scaled by the number of shares outstanding (NOSH) (Tsalavoutas et al., 2012; Barth et al., 2008).

In order to test our ancillary hypotheses, we run the same tests for the overall KPIs quality (OvKPIsRep) for financial and nonfinancial KPIs quality separately (FKPIsRep and NonFKPIsRep)

$13 \quad A W C A_{t}=\frac{W C_{t}-\left(\frac{W C_{t-1}}{s_{t-1}} \times s_{t}\right)}{T A_{t}}$, where $W C$ is non-cash working capital accruals computed as [(Current assets (WC02201) - cash\&equivalents (WC02001)) - (current liabilities (WC03101) short term debt(WC03051). $S$ and TA stand for sales and total assets (WC01001 and WC02999 respectively). 
and based on whether these are reported in the whole annual report or in the Business Review (OvKPIsSec, FKPIsSec, and NonFKPIsSec). To ensure the robustness of our tests, regressions (5) and (6) are estimated using both the KPIs' quality transformations (i.e., percentile dense rankings (QIAvKPIs_rank) and normal scores (QIAvKPIs_norm)).

Additionally, in estimating the regression models, we control for the cross-sectional correlations by using cluster-two by firm and year (see Gow et al., 2010; Petersen, 2009). Further, multicollinearity is checked with a variance inflation factor (VIF).

Finally, in order to address any concerns of endogeneity between KPIs disclosure quality and ICC, we also estimate 2SLS regressions. In the 2SLS specification, KPIs disclosure quality is treated as endogenous and the following variables are used as instruments in the first stage: Liquidity (current assets (WC02201) to current liabilities (WC03101)), Leverage (debt (WC03051) to book value of equity (WC03501)), BoardSize (total number of directors on the board; hand collected), RoleDuality (dummy variable equal to 1 if the chairman is the same person as the CEO of the firm, 0 otherwise; hand collected), ACmeetings (total number of audit committee meetings during the year; hand collected), CrossListing (dummy variable equal to 1 if the firm's shares are traded in foreign financial markets, 0 otherwise), and Industry fixed effects. Second stage is equal to equation (5). We then perform the Hausman test which is the most commonly used test providing a formal test on whether the instrumental variables estimator is significantly different from the OLS estimator (Larcker and Rusticus, 2010). If the $\mathrm{X}^{2}$ in the Hausman test is significant, the 2SLS estimators are better than OLS and vice versa.

\subsection{Sample selection process and data}

We examine a panel data set of UK firms over the five-year period from 2006 to 2010. We start with the 2011 Financial Times ranking to identify the top 350 UK firms based on market value. ${ }^{14}$

\footnotetext{
14 The vast majority of the annual reports for 2010 were issued during 2011. We consider the 2011 Financial Times ranking so as to allow information contained in the annual reports for 2010 to be priced by the market, capturing the relative size of our sample firms.
} 
Following the literature (e.g., Abraham and Cox, 2007; Beretta and Bozzolan, 2004), we then exclude financial firms, given their specific characteristics and the different framework for disclosure practices applicable to them. Subsequently, we randomly select firms so that each industry is represented by the same proportion as in the initial sample. In order to do this selection, we rank all of the firms in each industry by their market capitalisation, and we use systematic sampling by retaining the first firm in every industry as a starting point, then the third, the fifth, and so on. Following this procedure, we identify 102 firms (510 firm-year observations over the fiveyear period of 2006 to 2010). In a subsequent sampling step, we exclude various observations given data unavailability and other constraints. Panel A in Table 1 provides more details on the process applied in selecting our final sample (448 observations). In addition, Panel B provides a disaggregation of our sample across industries.

\section{TABLE 1 - ABOUT HERE}

We download annual reports from the companies' webpages or the Thomson One Banker database. We also download firms’ fundamental characteristics from Datastream, analysts’ forecasts from Institutional Brokers' Estimate System (I/B/E/S), and inflation rates forecasts from the Bank of England.

\section{Findings}

\subsection{Descriptive statistics}

We report the descriptive statistics for each control variable in Table $2 .{ }^{15}$ Data are presented before any procedure that accounts for the presence of outliers - see below. The mean (median) $M V$ of the sample is $£ 7.5$ (1.2) bn, while the standard deviation is $£ 17.3$ bn. This high variation is expected given that our sample firms are drawn from the FTSE 350 which includes the largest and most liquid shares in the UK. The mean (median) market to book value (M2B) is 4.5 (2.7) which suggests that financial markets believe that a considerable part of a firm's value is not represented by its

\footnotetext{
${ }^{15}$ The NOSH and Sal are not used as control variables. The former is used for scaling the variables in Eq. 6 and the latter for the calculation of the independent variables. We provide information about these for the interest of the reader.
} 
book value of equity. The mean (median) number of analysts following (AnFollow) is 14 (13), with a standard deviation of 7. Because we focus on disclosure, the ICC and the firm value, having a relative large number of analysts following each firm is desirable for two reasons: first, it confers robustness to our ICC measures because we have more forecasts to rely on when estimating the ICC; and second, it enhances the potential effect of the disclosure on the ICC and the firm value because there are more sophisticated investors who probably pay attention to that disclosure.

We note that these descriptive statistics show large differences between the mean and median values for variables. Untabulated results show that the distribution of $N I$ is negatively skewed, while the distribution of all other variables is positively skewed. Thus, we proceed by winsorising the independent variables which are not log-transformed at the $2^{\text {nd }}$ and $98^{\text {th }}$ percentiles to account for influential/outlying observations. After this procedure, untabulated results show that the distribution of our variables is less skewed. For example, the highest skewness before applying the winsorising procedure is exposed by $M 2 B$ and Dispersion (11.735 and 11.087 respectively). After winsorising our data, these variables expose significantly lower skewness (3.428 and 2.427 respectively). Hence, we use the winsorised data in our empirical analyses.

\section{TABLE 2 - ABOUT HERE}

Table 3 shows the levels of KPI disclosure quality with regard to what is disclosed in the whole annual report. These levels show that the mean (median) quality of the total KPIs disclosed in companies' annual reports increases significantly ( $p<0.01$ based on the Cuzick (1985) test) across the sample period (from 29\% (31\%) in 2006 to 44\% (44\%) in 2010). This increase results in a mean (median) quality of the total KPIs at 38\% (41\%). The aforementioned trend is mainly driven by an increase in the KPIs disclosure quality from 2006 to 2008; in fact, a T-test and a Mann-Whitney test show no significant difference between the scores for 2008 to 2009 and 2009 to 2010.

Similar results occur when exploring the quality levels of the disclosures of the financial and nonfinancial KPIs separately. When comparing the two sets of KPIs, we notice that the quality of nonfinancial KPIs disclosure tends to be lower than that of the financial KPIs. With regard to the 
period covered, the mean (median) for the former is 33\% (36\%) and the corresponding for the latter is 36\% (38\%). The T-test (Wilcoxon test) confirms that there is a statistically significant difference at the $1 \%$ level (10\% level) between the disclosure qualities of financial and nonfinancial KPIs.

In Panel C of Table 3, we disaggregate our sample firms across quality score groups. The information in this panel shows that only a few companies report overall KPIs disclosure with qualities higher than 60\%, and no company is identified with a KPI disclosure quality above $90 \%$. This result is mainly driven by the high quality of the financial KPIs reporting. Furthermore, we observe that there is at least one company in each year whose KPIs quality score is zero which means that it did not disclose any KPI or it disclosed some, but without reporting any of the qualitative characteristics suggested by ASB (2006).

\section{TABLE 3 - ABOUT HERE}

Given that our KPIs quality measure relies also on quantity, our untabulated results indicate that the mean (median) number of total KPIs disclosed in companies' annual reports increases significantly across the sample period ( $p<0.01$ based on the Cuzick (1985) test), moving from 6 (5) in 2006 to 10 (10) in $2010 .^{16}$ The same trend exists with regard to financial and nonfinancial KPIs separately. Similar to the results in Table 3, the positive trend in KPIs disclosure quantity is driven by an increase experienced from 2006 to 2008. In all of the years, there is at least one company which discloses no KPIs, thus being in explicit violation of the CA (2006). At the same time, there are always firms which seem to over report KPIs as the maximum number of KPIs reported ranges from 24 in 2009 to 87 in 2007. These findings are in line with the FRC (2009) report which inter alia points out that some companies report too many KPIs for all be key.

Table 4 shows the quality levels of the KPI disclosures with regard to what is disclosed in the Business Review only. As reported in Table 3, Table 4 shows that the mean (median) quality of total KPIs disclosed in the Business Review increases significantly ( $p<0.01$ based on the Cuzick (1985) test) across the sample period (from 28\% (29\%) in 2006 to 43\% (44\%) in 2010). As with the

\footnotetext{
${ }^{16}$ Tables reporting the relevant information discussed here are available on request.
} 
results in Table 3, this trend is driven by an increase in the KPIs disclosure quality from 2006 to 2008. The mean (median) quality of the total KPIs disclosed throughout the sample period is $37 \%$ (39\%). As these figures are lower than the corresponding ones with regard to the information disclosed throughout the whole annual report, they indicate that it is the quality of information disclosed in the Business Review that drives the quality of information disclosed in the annual report downwards.

Confirming the previous results from Table 3, we notice that the quality of the nonfinancial KPIs disclosure is lower than that of financial KPIs. The mean (median) for the former is 28\% (29\%) and the corresponding for the latter is 37\% (39\%). The T-test (Wilcoxon test) confirms that there is a statistically significant difference at the $1 \%$ level (1\% level) between our two sets of KPIs.

\section{TABLE 4 - ABOUT HERE}

Untabulated results on KPIs disclosure quantity show an increase in the number of KPIs disclosed within the Business Review as time goes by ( $p<0.01$ based on the Cuzick (1985) test), moving from 6 (5) in 2006 to 9 (8) in $2010 .^{17}$ The same trend is noticed with regard to financial and nonfinancial KPIs, and again the number of financial KPIs disclosed is always higher than that of the nonfinancial KPIs. The aforementioned trends are again driven by an increase in disclosure practices between 2006 and 2008. Additionally, it appears that the mean (median) number of nonfinancial KPIs disclosed in the Business Review (2 (1)) is lower than the corresponding number in the annual report (3 (2)) which means that this type of information is preferably conveyed in a different part of the annual report.

Table 5 reports more detailed information on the KPIs disclosed and on their disclosure quality. Panel A shows that eight out of the ten most commonly reported KPIs are financial, while only two are nonfinancial (i.e., employees accidents, ranked $6^{\text {th }}$, and lost time incidents, ranked $9^{\text {th }}$ ). The most commonly reported KPIs are related to earnings per share; in 58\% of our sample firms, a relevant KPI is reported. KPIs related to cash flows and revenues are also frequently reported across

\footnotetext{
${ }^{17}$ Tables reporting the relevant information discussed here are available upon request.
} 
our sample firms (57\% and 53\% respectively). The ten most common financial KPIs disclosed relate to information that could be obtained from the income statement (e.g., revenues and margins) and from the cash flow statement (e.g., dividends and capital expenditure). Our sample companies report these KPIs in their annual reports very frequently, varying from a maximum frequency of $58 \%$ to a minimum frequency of $13 \%$. The ten most common nonfinancial KPIs relate mostly to employees and environmental issues. However, we observe that this type of KPIs are more tailored to the nature of business of each individual firm, resulting in a much lower repetition of identical KPIs across many firms. More specifically, the frequencies of the ten most common nonfinancial KPIs vary from a maximum of $20 \%$ to a minimum of $2 \%$.

Panel B reports descriptive statistics on the qualitative characteristics suggested by the OFR (2006). We identified that our sample companies disclosed 3,842 different KPIs (2,422 financial; 1,420 nonfinancial) throughout the whole period. The most commonly fulfilled characteristics are definition of the KPIs (98\%) and the comparison with the corresponding amount for the financial year immediately preceding the current one (90\%). One of the lowest disclosed qualitative characteristics is the source of the underlying data used for the calculation of a KPI (37\%).

Overall, these descriptive statistics indicate that companies are not forthcoming in relation to certain types of KPI, especially those that relate to future related information. This is in line with the general narrative reporting literature in which there is consensus that companies are more forthcoming about past information than they are about future related information and that qualitative information dominates quantitative information. Litigation, proprietary cost issues, reputation and self-serving bias may be reasons for such disclosure behaviour. At the same time, these descriptive statistics indicate a wide variation on the information disclosed across companies. Such a variation may feed into companies’ level of cost of equity capital and valuation.

\section{TABLE 5 - ABOUT HERE}

Table 6 illustrates the ICC descriptive statistics for the full sample and for each year examined. The mean (median) $r_{A V}$ varies from a minimum of $8.7 \%(7.9 \%)$ in 2006 to a maximum of $12.6 \%$ 
(10.9\%) in 2008. Panel B presents a Cuzick (1985) test which shows no statistically significant trend in the ICC through the period examined. This lack of a trend can be explained by the information presented in Panel B. The ICC reaches its peak in 2008 and then drops significantly in 2009 ( $p<0.01$ based on a Mann-Whitney test; $p<0.05$ based on a T-test) while there is no statistical difference between the ICC in 2009 and 2010. Given that we use an average measure, Panel C gives the Pearson's correlation coefficients across the different models that we use in our ICC measure. All of the models are positively and significantly $(p<0.01)$ correlated. This correlation suggests that all four ICC measures capture similar information and that our average ICC is robust.

\section{TABLE 6 - ABOUT HERE}

\subsection{Bivariate analysis}

The Pearson's correlation coefficients between all of the variables are presented in Table 7. This shows that all of the proxies we use to capture the quality of the KPI disclosures correlate very positively and significantly ( $p<0.01)$. Regarding our first hypothesis $(\mathrm{H} 1)$, the preliminary evidence is a negative and statistically significant $(p<0.01)$ correlation between the ICC and the overall KPI disclosure quality. When looking at the disclosure quality of financial (H1.a) and nonfinancial KPIs (H1.b) separately, only the former correlates negatively and significantly with the ICC $(p<0.01)$. As far as our second set hypotheses is concerned (H2, H2.a and H2.b), all of the measures of the KPI disclosure quality are positively and significantly $(p<0.01)$ correlated with the market value $(M V)$, net income (NI), and analyst following (AnFollow).

\section{TABLE 7 - ABOUT HERE}

\subsection{Multivariate analysis}

Table 8 reports the results regarding our first set of hypotheses. Starting with the results presented in the two columns entitled 'Overall' (H1), the aggregate measure for the quality of KPI disclosure is not significantly correlated with the ICC. This result holds irrespective of whether the overall KPIs disclosure quality has been captured in the Business Review or the annual report as a whole. Instead, the return variance and analysts following play a significant role in explaining the ICC. 
However, this result can also be explained by the findings reported under the columns entitled 'Financial \& Nonfinancial' (with reference to H1.a and H1.b). These columns report the disaggregated effect of financial and nonfinancial KPIs disclosure quality on the ICC. These tests indicate that only financial KPIs disclosure quality has a negative and significant coefficient which means that the enhanced quality of this type of information contributes to a reduction of the ICC. The results hold irrespective of the transformation applied for the quality score and whether these are related to the KPIs disclosed in the annual report as a whole $(-0.029, p<0.05$, for dense rankings; $-0.007, p<0.05$, for normal scores) or in the Business Review only $(-0.027, p<0.05$, for dense rankings; -0.006, $p<0.10$, for normal scores). Drawing on the coefficient of FKPIsRep_rank (FKPIsSec_rank) and considering that the values of this variable lie between zero and one (see Equation 3 above), the results indicate the following. The firm with the highest quality of Financial KPIs reporting in our sample benefits by a $0.29 \%(0.27 \%)$ reduction in its cost of equity capital (i.e., 29 (27) basis points) compared to the firm with the lowest quality of Financial KPIs reporting in our sample. The return variance and analysts following continue to play a significant role in explaining the ICC. Finally, the results of the Hausman test reveals no endogeneity of disclosure quality ( $p>0.10$ ), thus confirming that results under OLS are correctly estimated (see last raw in Table 8).

The above findings lead us to conclude that the more companies follow the ASB (2006) guidelines for achieving best practice with regard to financial KPIs disclosure quality, the more they benefit with regard to their ICC. The same does not apply to nonfinancial KPIs disclosure quality. In fact, our results show that this type of information does not affect the cost of equity capital.

\section{TABLE 8 - ABOUT HERE}

Table 9 reports the results regarding our second set of hypotheses. As in the case with regard to the tests relating to the ICC, the aggregate measure for the quality of KPI disclosure is not correlated significantly with the market value (MV). This result also holds irrespective of whether the overall KPI disclosure quality has been captured in the Business Review or the annual report as a whole. 
However, when looking at the disaggregated effect of the disclosure quality of the financial and nonfinancial KPIs on the market value, we again note that only the financial KPI disclosure quality has a positive and significant coefficient. The results hold irrespective of the transformation applied for the quality score and whether the quality score relates to the KPIs disclosed in the annual report as a whole (1.348, $p<0.05$, for dense rankings; $0.320, p<0.10$, for normal scores) or in the Business Review only (1.349, $p<0.10$, for dense rankings; $0.321, p<0.10$, for normal scores). These findings suggest that this type of information is value relevant. In fact, drawing on the coefficient of FKPIsRep_rank (FKPIsSec_rank) and considering that the values of this variable lie between zero and one (see Equation 3 above), the results indicate the following. The firm with the highest quality of Financial KPIs reporting in our sample benefits by a $1.348 \%$ (1.349\%) increase in its market price per share compared to the firm with the lowest quality of Financial KPIs reporting in our sample.

\section{TABLE 9-ABOUT HERE}

The results reported for financial KPIs confirm the hypothesised economic consequence of disclosure. On the one hand, the literature suggests that corporate disclosure should reduce the cost of capital by enhancing the market liquidity (e.g., Diamond and Verrecchia, 1991; Easley and O’Hara, 2004) or reducing the estimation risk (e.g., Hughes et al., 2007; Lambert et al., 2007). On the other hand, corporate disclosure is able to affect managers' decisions, thus altering the distribution of future cash flows, which indirectly affects firm value (Lambert et al., 2007). In line with this literature, our results show that financial KPI disclosure quality reduces the cost of capital and is somewhat value relevant, meaning that this specific type of information is useful to investors and is able to reduce information asymmetries. Additionally, our results complement those of Iatridis (2008; 2011) who finds that UK firms having higher needs for capital provide disclosures of higher quality, suggesting that UK firms which make additional effort to provide disclosures of better quality achieving a reduction in their cost of capital. The fact that the significance of the two relations is different (strong for the ICC and weak for the firm value) is supported by the literature 
on the independent movements of the cost of capital and the firm value because of corporate disclosure (Pope and McLeay, 2011). Finally, we note that, as shown in Table 5 (Panel A), most of the financial KPIs reported relate to earnings, cash flows and rates of return. Thus, the results in Tables 8 and 9 regarding the relationship between quality of financial KPIs disclosure quality are in line with prior literature showing that earnings related information is value relevant for investors (e.g., Athanasoukou and Hussainey, 2014; Hussainey et al., 2003; Wang and Hussainey, 2013).

The results for nonfinancial KPIs can be interpreted in light of the CA (2006), which points out that these should only be disclosed 'when appropriate', thus being a sort of secondary source of information. Hence, managers are probably either ineffective at disclosing nonfinancial KPIs which are informative to investors or are reporting useful information but without a quality level which is sufficient for investors to get useful information. The latter is supported by the descriptive statistics in Tables 3 and 4 where we show that, on average, financial KPI disclosure quality is significantly higher than nonfinancial KPIs. Moreover, nonfinancial KPIs are extremely firm specific as we show in Table 5, where we document a very low percentage of frequency for the 10 most commonly nonfinancial KPIs reported. This variance in reporting of this type of information may result in investors to be provided with less comparable information compared to financial KPIs. Alternatively, such non-financial information might not be viewed as useful by investors anyway. All these might be the reasons for nonfinancial KPIs being value irrelevant.

Overall, we conclude that the more companies follow the ASB (2006) guidelines for achieving best practice with regard to financial KPIs disclosure quality, the more they benefit in terms of the cost of capital and their market value.

\section{Sensitivity analyses and additional tests ${ }^{18}$}

First, given the debate surrounding the validity of ICC measures, we rerun our regressions that identify the link between KPI disclosure quality and the cost of capital by using a single measure

\footnotetext{
${ }^{18}$ Tables reporting the relevant information discussed in this section are available on request.
} 
for the ICC. In particular, we use the $r_{M P E G}$ (Easton, 2004), since previous studies suggest that is best for ICC measures employing analyst forecasts (Botosan et al., 2011; Clarkson et al., 2013). Using this measure reduces our sample from 448 to 415 firm-year observations because of the difficulty in solving the equation with the $r_{M P E G}$. The results are the same as in the previous section: overall KPIs' disclosure quality is again not significantly correlated with ICC (negative sign of the coefficient). The financial KPI disclosure quality holds irrespective of the transformation applied for the quality scores and whether these are related to the KPIs disclosed in the annual report as a whole $(-0.027, p<0.01$, for dense rankings; $-0.007, p<0.05$, for normal scores) or in the Business Review only (-0.025, $p<0.05$, for dense rankings; $-0.006, p<0.05$, for normal scores). The Hausman test shows again no endogeneity problem in the OLS regressors estimation.

Second, because of the reduced sample size, we also rerun the regressions that identify the value relevance of the KPI disclosure quality. Once again, our results are robust in that the aggregate measure for the quality of the KPI disclosure and the nonfinancial KPIs are not correlated significantly with the market value. However, financial KPI disclosure quality is value relevant. In fact, the results of these additional tests, show a strong positive relation between the KPI disclosure quality and the market value when financial KPIs are disclosed in the annual report $(1.453, p<0.05$, for dense rankings; 0.366, $p<0.05$, for normal scores) or only in the Business Review (1.449, $p<0.05$, for dense rankings; 0.362, $p<0.05$, for normal scores).

Third, we reflect on our measure for the KPIs disclosure quality and we explore an alternative approach. We create a new measure for KPIs disclosure quality, which is inspired by the Saidin Index (Hodgdon et al., 2008) and does weight not equally the quality of each KPI. This new measure is a weighted average where the weights are calculated by considering the number of times a KPIs has been disclosed in a specific year in our sample. The weight applied to each KPI is calculated as the ratio between the times that k-th KPI was disclosed (numerator) on the number of KPIs disclosed for the full sample in a given year (denominator). Untubulated descriptive statistics as well as T-tests (Mann-Whitney tests) confirm that the means (medians) of our new measure for 
Overall and Financial KPIs disclosure quality are significantly different $(p<0.05)$ from the ones we employ in the results discussed in the previous section. Subsequently, we employ our new measure in multivariate analyses. In order to be consistent with our main tests, we also transformed it employing percentile rankings and normal scores. Our new tests reveal a negative and significant relationship between the weighted index and ICC $(p<0.05)$ compared to insignificant relationship reported in the previous section. These results can be explained based on the rationale we use in developing our new measure for KPIs disclosure quality. Our new measure weights KPIs according to their 'popularity'. Given that financial KPIs are more 'popular' than nonfinancial KPIs, the new measure for the overall quality of KPIs is more influenced by financial than by nonfinancial KPIs. In fact, when exploring the relationship between the disclosure quality of financial KPIs and ICC, results employing our new weighted measure are consistent with those reported in the main tests presented earlier. We find a negative and statistically significant relationship between our weighted measure and ICC $(p<0.05)$. Finally, the results with regard to the second hypothesis become weaker, as we find no significant relation between our weighted measure and market values

Fourth, we also analyse the link between the KPI disclosure quantity and the ICC, as well as its value relevance. When performing these tests, beyond using dense rankings and normal scores, we use two additional transformations: the square root and the log-transformation. These two result in loosing many observations when either the number of financial or nonfinancial KPIs disclosed as zero. The results show that none of the KPI disclosure quantity dimensions (overall, financial, and nonfinancial) is related to the cost of capital or is value relevant. These results are consistent with the FRC $(2007,2009)$ reports which draw attention to the quality rather than the quantity of KPI reporting. In fact, reporting a large number of KPIs does not appear to reduce information asymmetries. The disclosure of KPIs without directors defining, explaining, and linking each KPI to the financial or nonfinancial performance of the company results in the provision of uninterpretable information, which does not have an impact on the cost of equity capital and the market value. 


\section{Conclusions}

We contribute to the disclosure literature by being the first study to measure the quality of KPI reporting in companies' annual reports and examining its economic consequences. In particular, we analyse the impact of KPI disclosure quality on firms' cost of capital and firm value. In order to measure the quality of corporate disclosure, we use a manual content analysis that considers all of the qualitative attributes of the information suggested by the ASB (2006) statement of best practice. An average of four models is used to estimate the ICC. Our analyses are based on a panel data set of 448 UK annual reports throughout the period of 2006 to 2010.

Although a substantial body of literature exists on the economic consequences of disclosure in general, very little is known about the role of KPI reporting which is brought forward by regulators. Our findings indicate that only the disclosure quality of financial KPIs has a strong negative impact on the ICC and a weak positive relation with firm value. In fact, the quantity of KPI reporting has no effect on the cost of capital or the market value.

Policy makers can take some comfort from the evidence that the KPIs reporting on financial KPIs does have an influence, but they might also be interested in exploring why the quality of nonfinancial KPIs is relatively low and does not result in any economic consequences. Our study should also be relevant to compilers of annual reports because firms' good disclosure practices on financial KPIs lead to a reduction in the ICC and to higher market value, while just disclosing high numbers of KPIs does not result in any benefit.

This study is subject to limitations. Although the measures of the ICC that we use are those most commonly used in the literature, there is an ongoing debate on which measures provide a good proxy for the cost of equity capital. Moreover, sample firms are based on the FTSE 350, which is among the most liquid and important UK firms. This leaves an open research question about the economic consequences of the quality of the KPIs disclosure among smaller and less liquid firms in the UK or in other countries. This question provides a clear avenue for future research given that KPIs disclosure is mandatory across the EU. 


\section{References}

Athanasoukou, V., Hussainey, K., 2014. The perceived credibility of forward-looking performance disclosures. Accounting and Business Research, 44 (3), 227-259.

Abraham, S., Cox, P., 2007. Analysing the determinants of narrative risk information in UK FTSE 100 annual reports. The British Accounting Review 39 (3), 227-248.

Accounting Standard Board (ASB), 2006. Reporting statement: Operating and financial review. Accounting Standard Board, London, UK.

Advisory Committee on Improvements to Financial Reporting (ACIFR), 2008. Final Report of the Advisory Committee on Improvements to Financial Reporting to the United States Securities and Exchange Commission. Advisory Committee on Improvements to Financial Reporting, Washington, DC, USA.

Baek, J., Kang, J., Park, K., 2004. Corporate governance and firm value: evidence from the Korean financial crisis. Journal of Financial Economics 71 (2), 265-313.

Barth, M. E., Landsman, W. R., Lang, M., 2008. International accounting standards and accounting quality. Journal of Accounting Research 46 (3), 467-498.

Beattie, V., McInnes, B., Fearnley, S., 2004. A methodology for analysing and evaluating narratives in annual reports: a comprehensive descriptive profile and metrics for disclosure quality attributes. Accounting Forum 28(3), 205-236.

Beretta, S., Bozzolan, S., 2004. A framework for the analysis of firm risk communication. The International Journal of Accounting 39 (3), 265-288.

Beyer, A., Cohen, D. A., Lys, T. Z., Walther, B. R., 2010. The financial reporting environment: review of the recent literature. Journal of Accounting and Economics 50 (2-3), 296-343.

Botosan, C., 1997. Disclosure level and the cost of equity capital. The Accounting Review 72 (3), 323-349.

Botosan, C., Plumlee, M., 2002. A re-examination of disclosure levels and expected cost of equity capital. Journal of Accounting Research 40 (1), 21-40.

Botosan, C., Plumlee, M., 2005. Assessing alternative proxies for the expected risk premium. The Accounting Review 80 (1), 21-53.

Botosan, C., Plumlee, M., Wen, H., 2011. The relation between expected returns, realized returns, and firm risk characteristics. Contemporary Accounting Research 28 (4), 1085-1122.

Cheung, Y., Jiang, P., Tan, W., 2010. A transparency disclosure index measuring disclosures: Chinese listed companies. Journal of Accounting and Public Policy 29 (3), 259-280.

Clarkson, P. M., Fang, X., Li, Y., Richardson, G., 2013. The relevance of environmental disclosures: Are such disclosures incrementally informative? Journal of Accounting and Public Policy 32 (5), 410-431.

Clarkson, P., Guedes, J., Thompson, R., 1996. On the diversification, observability and measurement of estimation risk. Journal of Financial and Quantitative Analysis 31 (1), 69-84.

Claus, J., Thomas, J., 2001. Equity premia as low as three percent? Evidence from analysts' earnings forecasts for domestic and international stock markets. The Journal of Finance 56 (5), 1629-1666.

Companies Act, 2006. UK Companies Act 2006, London, UK. Available at http://www.legislation.gov.uk/ukpga/2006/46/pdfs/ukpga_20060046_en.pdf

Cooke, T., 1992. The impact of size, stock market listing and industry type on disclosure in the annual reports of Japanese listed corporations. Accounting and Business Research 87 (22), 229-237. 
Cooke, T., 1998. Regression analysis in accounting disclosure studies. Accounting and Business Research 28 (3), 209-224.

Cuzick, J., 1985. A Wilcoxon-type test for trend. Statistics in Medicine 87 (4), 87-89.

Daske, H., Hail, L., Leuz, C., Verdi, R., 2008. Mandatory IFRS reporting around the world: Early evidence on the economic consequences. Journal of Accounting research 46 (5), 1085-1142.

Department for Environment, Food and Rural Affairs (DEFRA), 2006. Environmental Key Performance Indicators: Reporting Guidelines for UK Businesses. Department for Environment, Food and Rural Affairs, London, UK.

Department for Environment, Food and Rural Affairs (DEFRA), 2012. Reporting Guidance for Business on Environmental Key Performance Indicators: a consultation on Guidance for UK Businesses. Department for Environment, Food and Rural Affairs, London, UK.

Diamond, D. W., Verrecchia, R. E., 1991. Disclosure, Liquidity, and the Cost of Capital. Journal of Finance 46 (4), 1325-1359.

Dorestani, A., Rezaee, Z., 2011. Key performance indicators and analysts' earnings forecast accuracy: an application of content analysis. Asian Academy of management Journal of Accounting and Finance, 7 (2), 79-102.

Easley, D., O’Hara, M., 2004. Information and the cost of capital. The Journal of Finance 59 (4), 1553-1583.

Easton, P., 2004. PE ratios, PEG ratios, and estimating the implied expected rate of return on equity capital. The Accounting Review 79 (1), 73-96.

Easton, P., Monahan, S., 2005. An evaluation of the reliability of accounting based measures of expected returns: A measurement error perspective. The Accounting Review 80 (2), 501-538.

Edwards, E., Bell, P., 1961. The theory and measurement of business income. University of California Press, Berkeley, USA.

European Union (EU) Accounting and Modernisation Directive, 2003. Directive 2003/51/EC of the European Parliament and of the Council. Available at http://eurlex.europa.eu/LexUriServ/LexUriServ.do?uri=OJ:L:2003:178: 0016:0022:EN:PDF

Fama, E., French, K. R., 2002. The equity premium. The Journal of Finance 57 (2), 637659.

Financial Reporting Council (FRC), 2007. A Review of Narrative Reporting by UK Listed Companies in 2006. Financial Reporting Council, London, UK.

Financial Reporting Council (FRC), 2009. A Review of Narrative Reporting by UK Listed Companies in 2008/2009. Financial Reporting Council, London, UK.

Gebhardt, W., Lee, C., Swaminathan, B., 2001. Towards an ex-ante cost of capital. Journal of Accounting Research 39 (1), 135-176.

Glaum, M., Schmidt, P., Street, D. L., Vogel, S., 2013. Compliance with IFRS3- and IAS36required disclosures across 17 European countries: company- and country-level determinants. Accounting and Business Research 43 (3), 163-204.

Gode, D., Mohanram, P., 2003. Inferring the cost of capital using the Ohlson-Juettner model. Review of Accounting Studies 8 (3), 399-431.

Gow, I. D., Ormazabal, G., Taylor, D. J., 2010. Correcting for cross-sectional and timeseries dependence in accounting research. The Accounting Review 85 (2), 483-512.

Hail, L., 2002. The Impact of Voluntary Corporate Disclosures on the Ex Ante Cost of Capital for Swiss Firms. European Accounting Review 11 (4), 741-743.

Hail, L., Leuz, C., 2006. International differences in the cost of equity capital: Do legal institutions and securities regulation matter? Journal of Accounting Research 44 (3), 485-531. 
Hassan, O., Romilly, P., Giorgioni, G., Power, D., 2009. The value relevance of disclosure: Evidence from the emerging capital market of Egypt. The International Journal of Accounting 44 (1), 79-102.

Healy, P. M., Hutton, A., Palepu, K. G., 1999. Stock performance and intermediation changes surrounding sustained increases in disclosure. Contemporary Accounting Research 16 (3), 485-520.

Healy, P.M., Palepu, G., 2001. Information asymmetry, corporate disclosure and capital markets: a review of the empirical disclosure literature. Journal of Accounting and Economics 31 (1-3), 405-440.

Hodgdon, C., Tondkar, R., Adhikari, A., \& Harless, D., (2009). 'Compliance with International Financial Reporting Standards and auditor choice: New evidence on the importance of the statutory audit', The International Journal of Accounting, Vol. 44, No.1, pp.33-55.

Hou, K., van Dijk, M. A., Zhang, Y., 2012. The implied cost of capital: A new approach. Journal of Accounting and Economics 53 (3), 504-526.

Hughes, J. S., Liu, J., Liu, J., 2007. Information asymmetry, diversification, and cost of capital. The Accounting Review 82 (3), 705-729.

Hussainey, K., Schleicher, T., Walker, M., 2003. Undertaking large-scale disclosure studies when AIMR-FAF ratings are not available: The case of prices leading earnings. Accounting and Business Research 33 (4), 275-294.

Iatridis, G. 2008. Accounting disclosure and firms' financial attributes: Evidence from the UK stock market. International Review of Financial Analysis 17 (2), 219-241.

Iatridis, G. 2011. Accounting disclosures, accounting quality and conditional and unconditional conservatism. International Review of Financial Analysis 20 (2), 88102.

International Accounting Standards Board (IASB), 2010. IFRS Practice Statement. Management Commentary: A framework for presentation. International Accounting Standards Board Foundation, London, UK.

Jiao, Y., 2011. Corporate disclosure, market valuation, and firm performance. Financial Management 40 (13), 647-676.

Kim, Y., Li, H., Li., S., 2012. Does eliminating the Form 20-F reconciliation from IFRS to U.S. GAAP have capital market consequences? Journal of Accounting and Economics 53 (1-2), 249-270.

Kothari, S. P., Li, X., Short, J. E., 2009. The effect of disclosures by management, analysts, and financial press on cost of capital, return volatility, and analyst forecasts: a study using content analysis. The Accounting Review 84 (5), 1639-1670.

Lambert, R. A., Leuz, C., Verrecchia, R. E., 2007. Accounting information, disclosure, and the cost of capital. Journal of Accounting Research 45 (2), 385-420.

Larcker, D.F., Rusticus, T.O., 2010. On the use of instrumental variables in accounting research. Journal of Accounting and Economics 49 (2), 186-205.

Leuz, C., Wysocki, P., 2008. Economic consequences of financial reporting and disclosure regulation: a review and suggestions for future research. Resource document. Social Science Research network http://papers.ssrn.com/sol3/papers.cfm? abstract_id=1105398.

Li, S., 2010. Does mandatory adoption of International Financial Reporting Standards in the European Union reduce the cost of equity capital? The Accounting Review 85 (2), 607-636.

Marra, A., Mazzola, P., Prencipe, A., 2011. Board monitoring and earnings management pre- and post-IFRS. The International Journal of Accounting 46 (2), 205-230. 
Mazzi, F., Andrè, P., Dionysiou, D., Tsalavoutas, I., 2014. Goodwill related mandatory disclosure and the cost of equity capital. Resource document. Social Science Research network http://papers.ssrn.com/sol3/papers.cfm?abstract_id=2464154.

Nikolaev, V., Van Lent, L., 2005. The endogeneity bias in the relation between cost-of-debt capital and corporate disclosure policy. European Accounting Review 14 (4), 677-724.

Ohlson, J., 1995. Earnings, book value, and dividends in security valuation. Contemporary Accounting Research 11 (2), 661-687.

Petersen, M. A., 2009. Estimating standard errors in finance panel data sets: comparing approaches. The Review of Financial Studies 22 (1), 435-480.

Pope, P. F., McLeay, S. J., 2011. The European IFRS experiment: objectives, research challenges and some early evidence. Accounting and Business Research 41 (3), 233266

Richardson, A. J., Welker, M., 2001. Social disclosure, financial disclosure and the cost of equity capital. Accounting, Organisations and Society 26 (7-8), 597-616.

Security and Exchange Commission (SEC), 2003. Interpretation: Commission Guidance Regarding Management's Discussion and Analysis of Financial Condition and Results of Operations - 17 CFR Parts 211, 231 and 241 - Release Nos. 33-8350; 34-48960; FR72. Available at http://www.sec.gov/rules/interp/33-8350.htm

Tauringana, V., Mangena, M., 2009. The influence of the business review on reporting key performance indicators in the UK media sector. Edinburgh: The Institute of Chartered Accountants of Scotland.

Tsalavoutas, I., André, P., Evans, L., 2012. The transition to IFRS and the value relevance of financial statements in Greece', The British Accounting Review, 44 (4), 262-277.

Tsalavoutas, I., Evans, L., Smith, M., 2010. Comparison of two methods for measuring compliance with IFRS mandatory disclosure requirements. Journal of Applied Accounting Research 11 (3), 213-228.

Uyar, A., Kiliç, M., 2012. Value relevance of voluntary disclosure: evidence from Turkish firms. Journal of Intellectual Capital 13 (3), 363-376.

Wang, M., Hussainey, K., 2013. Voluntary forward-looking statements driven by corporate governance and their value relevance. Journal of Accounting and Public Policy 32 (3), 26-49. 
Table 1 - Sample summary statistics

PANEL A - SAMPLE SELECTION PROCESS

The sample selection starting point is the top 350 UK firms based on market capitalisation, according to the Financial Times’ 2011 ranking. Financial firms are excluded. Subsequently, 102 firms are randomly selected, while representation of each industry is maintained at the same proportion as in the initial samples. In order to maintain this proportion, systematic sampling is used by choosing as a starting point the first company in every industry according to its market capitalisation, then by selecting the third, the fifth and so on.

\begin{tabular}{|c|c|}
\hline 510 & starting observations [102 firms for 5 years $(2006 ; 2007 ; 2008 ; 2009$; and 2010$)]$ \\
\hline $\begin{array}{c}n \text { observations } \\
\text { excluded thereafter }\end{array}$ & Reason for exclusion \\
\hline 2 & KPI’s regulation not applicable in 2006 (because of year-end date) \\
\hline 27 & no analyst following \\
\hline 31 & missing data on DataStream or IBES \\
\hline 2 & unable to solve at least one ICC model because of data unavailability \\
\hline 62 & total number of observations excluded \\
\hline 448 & final sample \\
\hline \multicolumn{2}{|r|}{ PANEL B - SAMPLE CONSTITUENTS BY INDUSTRY ${ }^{\mathrm{a}}$} \\
\hline Industry & Percentage \\
\hline Basic Materials & 7.8 \\
\hline Consumer Goods & 13.4 \\
\hline Consumer Services & 18.7 \\
\hline Health Care & 4.5 \\
\hline Industrials & 32.1 \\
\hline Oil \& Gas & 9.2 \\
\hline Technology & 7.6 \\
\hline Telecommunications & 2.2 \\
\hline Utilities & 4.5 \\
\hline TOTAL & 100.0 \\
\hline
\end{tabular}

${ }^{\mathrm{a}}$ Industries are listed according to the Industry Classification Benchmark.

Table 2 - Descriptive statistics for independent variables

\begin{tabular}{|c|c|c|c|c|c|c|}
\hline Variable & $\bar{n}$ & Mean & St. dev & $25^{\text {th }}$ perc & Median & $75^{\text {th }}$ perc \\
\hline$M V^{\mathrm{a}}$ & 448 & 7.46 & 17.30 & 0.59 & 1.24 & 3.65 \\
\hline$B V^{\mathrm{a}}$ & 448 & 3.35 & 11.60 & 0.19 & 0.49 & 1.71 \\
\hline$M 2 B$ & 448 & 4.46 & 11.21 & 1.64 & 2.72 & 4.06 \\
\hline$N I^{\mathrm{a}}$ & 448 & 0.43 & 1.80 & 0.03 & 0.07 & 0.22 \\
\hline $\mathrm{Sal}^{\mathrm{a}}$ & 448 & 5.94 & 19.70 & 0.53 & 1.34 & 3.60 \\
\hline SalG & 448 & 0.17 & 0.39 & 0.03 & 0.10 & 0.22 \\
\hline$T A^{\mathrm{a}}$ & 448 & 8.07 & 22.70 & 0.60 & 1.39 & 5.06 \\
\hline$A W C A$ & 448 & 0.04 & 0.04 & 0.01 & 0.02 & 0.05 \\
\hline$N O S H^{\mathrm{b}}$ & 448 & 1.30 & 5.75 & 0.132 & 0.288 & 0.883 \\
\hline$r V a r$ & 448 & 0.008 & 0.014 & 0.002 & 0.003 & 0.009 \\
\hline Dispersion & 448 & 3.29 & 7.54 & 0.73 & 1.53 & 3.46 \\
\hline AnFollow & 448 & 14 & 7 & 8 & 13 & 18 \\
\hline
\end{tabular}

$M V$ is the market value of equity (WC08001); $B V$ is the book value of equity (WC03501); $M 2 B$ is the market value to the book value of equity (WC08001/WC03501); NI is the net income (WC01751); Sal is the sales (WC01001); SalG is the sales growth computed as $\left(\right.$ Sales $_{t}-$ Sales $\left._{t-1}\right) /$ Sales $_{t-1}$; TA is the total assets (WC02999); AWCA is the absolute value of the abnormal working capital accruals scaled by the end-of-theyear total assets calculated according to Marra et al. (2011); NOSH is the number of shares (NOSH); rVar is the return variance over the financial year computed as $\ln \left(R I_{t_{-11}} / R I_{t_{0}}\right)$; Dispersion is the EPS forecasts standard deviation from IBES (STDEV); and AnFollow is the number of analysts following from IBES (NUMEST).

${ }^{a}$ GBP billions.

${ }^{\mathrm{b}}$ Billions. 
Table 3 - KPIs disclosure quality in the annual report ${ }^{a}$

PANEL A - DESCRIPTIVE STATISTICS BY YEAR

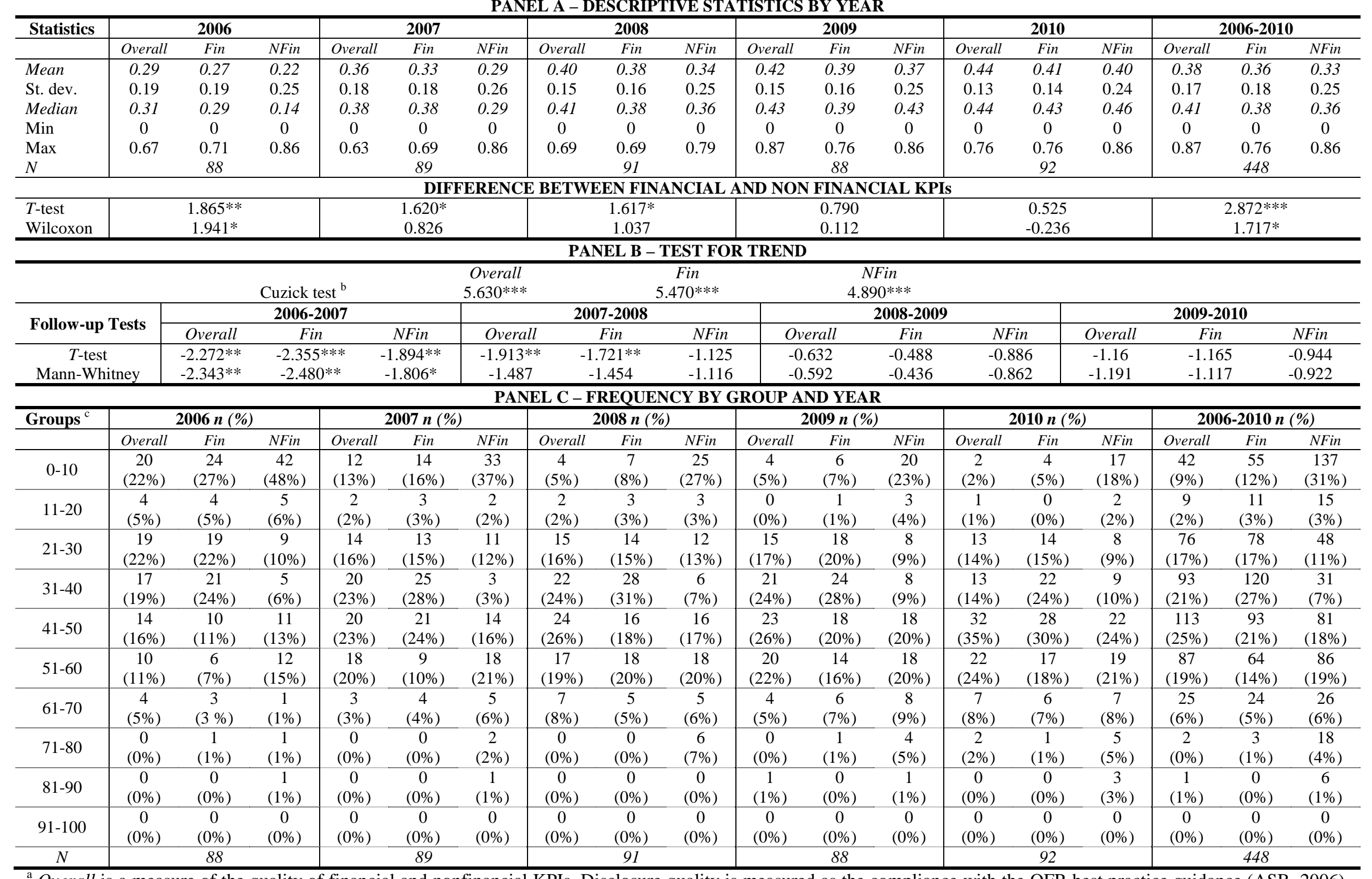

${ }^{\mathrm{a}}$ Overall is a measure of the quality of financial and nonfinancial KPIs. Disclosure quality is measured as the compliance with the OFR best practice guidance (ASB, 2006).

See subsection 3.2 for a detailed description of the measure of the KPI’s disclosure quality. Fin and NFin indicate the quality of financial and nonfinancial KPIs respectively.

${ }^{\mathrm{b}}$ The Cuzick (1985) test is the non-parametric test for the trend across ordered groups. ${ }^{\mathrm{c}}$ Groups are defined as the percentage of disclosure quality of KPIs, where zero means the poorest quality and $100 \%$ means the best practice. *, **, *** denote significance at the $10 \%, 5 \%$, and $1 \%$ levels respectively. 
Table 4 -KPIs disclosure quality in the Business Review only ${ }^{\text {a }}$

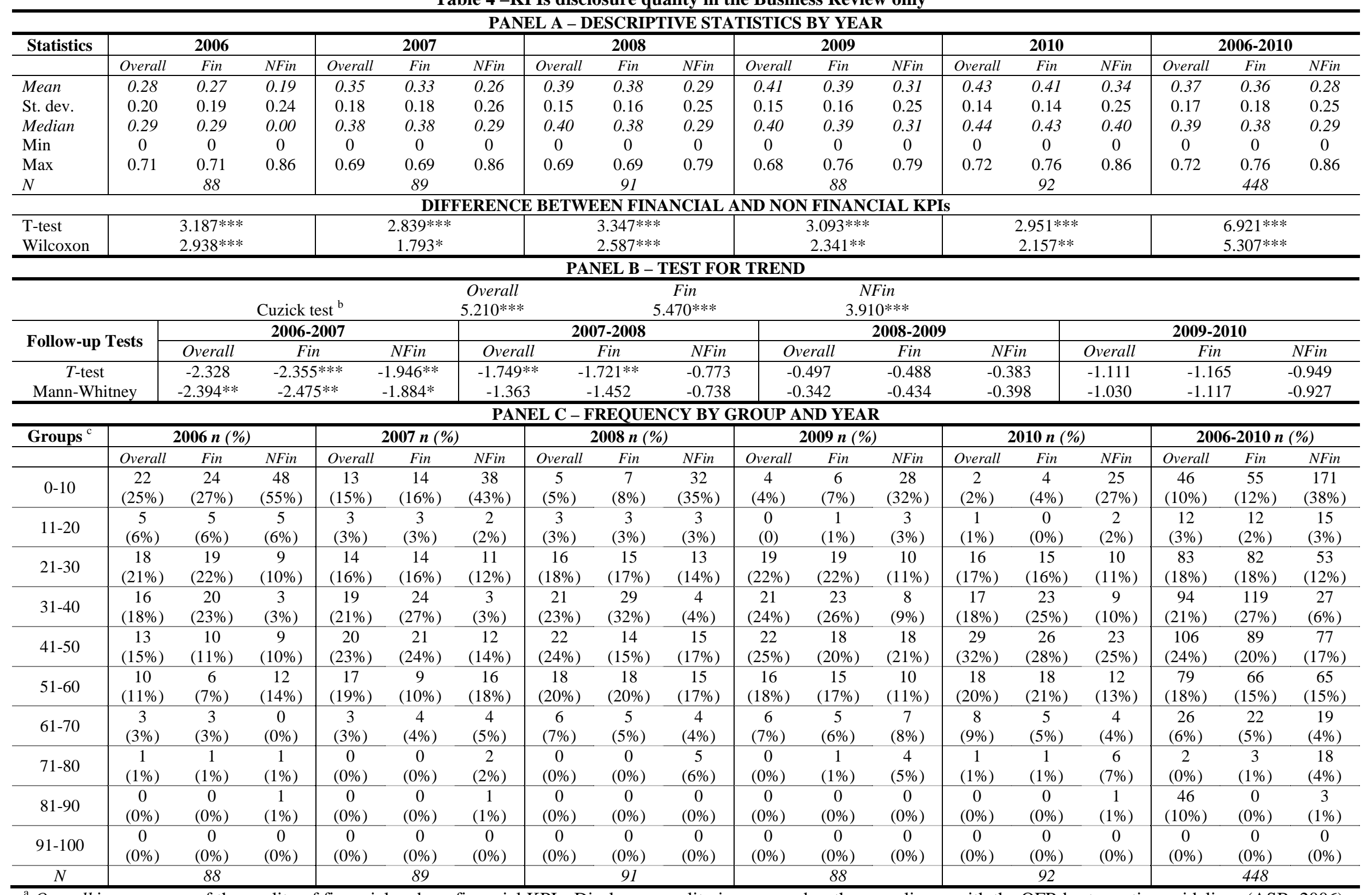

${ }^{a}$ Overall is a measure of the quality of financial and nonfinancial KPIs. Disclosure quality is measured as the compliance with the OFR best practice guidelines (ASB, 2006). See subsection 3.2 for a detailed description of the measure of the KPI's disclosure quality. Fin and NFin indicate the quality of financial and nonfinancial KPIs respectively.

${ }^{b}$ The Cuzick (1985) test is a nonparametric test for the trend across ordered groups. ${ }^{\mathrm{c}}$ Groups are defined as the percentage of disclosure quality of KPIs, where zero means the poorest quality and $100 \%$ means the best practice. The *, **, *** denote significance at the $10 \%, 5 \%$, and $1 \%$ levels respectively. 
Table 5 - FREQUENCES OF REPORTED KPIS AND THE QUALITATIVE CHARACTERISTICS RELATED TO KPIS REPORTED PANEL A - TEN MOST COMMONLY REPORTED KPIs

\begin{tabular}{|c|c|c|c|c|c|c|c|c|c|c|c|c|c|c|c|c|c|c|}
\hline \multicolumn{5}{|c|}{ Financial and NonFinancial combined } & \multicolumn{7}{|c|}{ Financial } & \multicolumn{7}{|c|}{ NonFinancial } \\
\hline \multicolumn{2}{|c|}{$K P I$} & $n$ & \multicolumn{2}{|c|}{$\%$} & \multicolumn{4}{|c|}{ KPI } & $n$ & \multicolumn{2}{|c|}{$\%$} & \multicolumn{4}{|c|}{ KPI } & $n$ & \multicolumn{2}{|r|}{$\%$} \\
\hline \multicolumn{2}{|l|}{ Earnings per share } & 258 & \multicolumn{2}{|c|}{$58 \%$} & \multicolumn{4}{|c|}{ Earnings per share } & 258 & \multicolumn{2}{|c|}{$58 \%$} & \multicolumn{4}{|c|}{ Employee accidents } & 89 & \multicolumn{2}{|r|}{$20 \%$} \\
\hline \multicolumn{2}{|l|}{ Cash flow } & 255 & \multicolumn{2}{|c|}{$57 \%$} & \multicolumn{4}{|c|}{ Cash flow } & 255 & \multicolumn{2}{|c|}{$57 \%$} & \multicolumn{4}{|c|}{ Lost time incidents } & 76 & \multicolumn{2}{|r|}{$17 \%$} \\
\hline \multicolumn{2}{|l|}{ Revenue } & 239 & \multicolumn{2}{|c|}{$53 \%$} & \multicolumn{4}{|c|}{ Revenue } & 239 & \multicolumn{2}{|c|}{$53 \%$} & \multicolumn{4}{|c|}{ Carbon dioxide emissions } & 43 & \multicolumn{2}{|r|}{$10 \%$} \\
\hline \multicolumn{2}{|l|}{ Operating profit } & 134 & & $\%$ & Operat & g profit & & & 134 & & $\%$ & Staff tu & nover & & & 34 & & $8 \%$ \\
\hline Sales & & 117 & & $\%$ & Sales & & & & 117 & & $\%$ & Water & onsumpt & & & 25 & & $6 \%$ \\
\hline Employee accidents & & 89 & & $\%$ & Operat & g margi & & & 84 & & $\%$ & Employ & ee engag & ment & & 24 & & $5 \%$ \\
\hline Operating margin & & 84 & & $\%$ & Return & n capita & employe & & 80 & & $3 \%$ & Employ & ee numb & & & 24 & & $5 \%$ \\
\hline Return on capital employed & & 80 & & $3 \%$ & Divide & & & & 62 & & $1 \%$ & Energy & consump & & & 10 & & $2 \%$ \\
\hline Lost time incidents & & 76 & & $\%$ & Return & n sales & & & 60 & & $3 \%$ & Manag & ment tur & over & & 9 & & $2 \%$ \\
\hline Dividends & & 62 & & $\%$ & Capital & Expendi & & & 59 & & $\%$ & Backlo & & & & 8 & & $2 \%$ \\
\hline & & & & $\overline{A N E L}$ & $\overline{B-Q U}$ & LITA & IVE C & $\overline{\text { IARA }}$ & TERIS & ICS'1 & 2EAK & $\overline{\mathbf{O W N}}$ & & & & & & \\
\hline $\begin{array}{c}\text { Qualitative } \\
\text { Characteristic }^{\mathrm{d}}\end{array}$ & & 2006 & & & 2007 & & & 2008 & & & 2009 & & & 2010 & & & 006-201 & \\
\hline & $\begin{array}{c}\begin{array}{c}\text { Overall } \\
n=560\end{array} \\
\end{array}$ & $\begin{array}{c}\text { Fin } \\
n=392 \\
\end{array}$ & $\begin{array}{c}\text { NFin } \\
n=168\end{array}$ & $\begin{array}{c}\begin{array}{c}\text { Overall } \\
n=710\end{array} \\
\end{array}$ & $\begin{array}{c}\text { Fin } \\
n=448 \\
\end{array}$ & $\begin{array}{c}\text { NFin } \\
n=262 \\
\end{array}$ & $\begin{array}{c}\text { Overall } \\
n=794 \\
\end{array}$ & $\begin{array}{c}\quad \text { Fin } \\
n=512 \\
\end{array}$ & $\begin{array}{c}\text { NFin } \\
n=282 \\
\end{array}$ & $\begin{array}{c}\text { Overall } \\
n=859 \\
\end{array}$ & $\begin{array}{c}\text { Fin } \\
n=520\end{array}$ & $\begin{array}{c}\text { NFin } \\
n=339 \\
\end{array}$ & $\begin{array}{l}\text { Overall } \\
n=919 \\
\end{array}$ & $\begin{array}{c}\text { Fin } \\
n=550\end{array}$ & $\begin{array}{c}\text { NFin } \\
n=369\end{array}$ & $\begin{array}{c}\text { Overall } \\
n=3,842 \\
\end{array}$ & $\begin{array}{c}\text { Fin } \\
n=2,422\end{array}$ & $\begin{array}{c}\text { NFin } \\
n=1,420\end{array}$ \\
\hline Definition & $97 \%$ & $97 \%$ & $95 \%$ & $98 \%$ & $98 \%$ & $98 \%$ & $98 \%$ & $98 \%$ & $97 \%$ & $98 \%$ & $98 \%$ & $97 \%$ & $98 \%$ & $99 \%$ & $97 \%$ & $98 \%$ & $98 \%$ & $97 \%$ \\
\hline Purpose & $43 \%$ & $39 \%$ & $54 \%$ & $49 \%$ & $45 \%$ & $56 \%$ & $58 \%$ & $51 \%$ & $71 \%$ & $63 \%$ & $59 \%$ & $70 \%$ & $71 \%$ & $65 \%$ & $80 \%$ & $59 \%$ & $53 \%$ & $69 \%$ \\
\hline Source of data & $27 \%$ & $28 \%$ & $26 \%$ & $31 \%$ & $31 \%$ & $32 \%$ & $41 \%$ & $38 \%$ & $47 \%$ & $39 \%$ & $37 \%$ & $44 \%$ & $40 \%$ & $37 \%$ & $45 \%$ & $37 \%$ & $34 \%$ & $41 \%$ \\
\hline Quantified target & $6 \%$ & $4 \%$ & $13 \%$ & $12 \%$ & $9 \%$ & $17 \%$ & $12 \%$ & $7 \%$ & $21 \%$ & $13 \%$ & $8 \%$ & $21 \%$ & $15 \%$ & $9 \%$ & $24 \%$ & $12 \%$ & $7 \%$ & $20 \%$ \\
\hline Commentary & $2 \%$ & $1 \%$ & $2 \%$ & $5 \%$ & $5 \%$ & $5 \%$ & $5 \%$ & $3 \%$ & $8 \%$ & $7 \%$ & $5 \%$ & $9 \%$ & $10 \%$ & $8 \%$ & $13 \%$ & $6 \%$ & $5 \%$ & $9 \%$ \\
\hline $\begin{array}{l}\text { Comparison with } \\
\text { previous year }\end{array}$ & $89 \%$ & $91 \%$ & $84 \%$ & $91 \%$ & $94 \%$ & $84 \%$ & $91 \%$ & $96 \%$ & $83 \%$ & $88 \%$ & $93 \%$ & $79 \%$ & $90 \%$ & $94 \%$ & $83 \%$ & $90 \%$ & $94 \%$ & $83 \%$ \\
\hline Adjustments & $14 \%$ & $13 \%$ & N.A. & $18 \%$ & $17 \%$ & N.A. & $23 \%$ & $23 \%$ & N.A. & $24 \%$ & $24 \%$ & N.A. & $24 \%$ & $24 \%$ & N.A. & $21 \%$ & $21 \%$ & N.A. \\
\hline Changes & $4 \%$ & $4 \%$ & $3 \%$ & $5 \%$ & $7 \%$ & $2 \%$ & $8 \%$ & $6 \%$ & $11 \%$ & $8 \%$ & $7 \%$ & $11 \%$ & $7 \%$ & $6 \%$ & $7 \%$ & $7 \%$ & $6 \%$ & $7 \%$ \\
\hline
\end{tabular}

total number of observations $(n=448)$

${ }^{\mathrm{b}} \%$ indicates the percentage relative to the total number of observations ( $\left.n=448\right)$ vary depending on the number of KPIs disclosed each year in each category (overall, financial and nonfinancial) and on the times it was applicable.

${ }^{c}$ Overall stands for financial and nonfinancial KPIs combined. Fin and NFin indicate financial and nonfinancial KPIs respectively.

${ }^{\mathrm{d}}$ Qualitative characteristics for KPIs disclosure as suggested by the OFR (ASB, 2006) are explained in Appendix A. 
Table 6 - Information regarding the implied cost of capital (ICC)

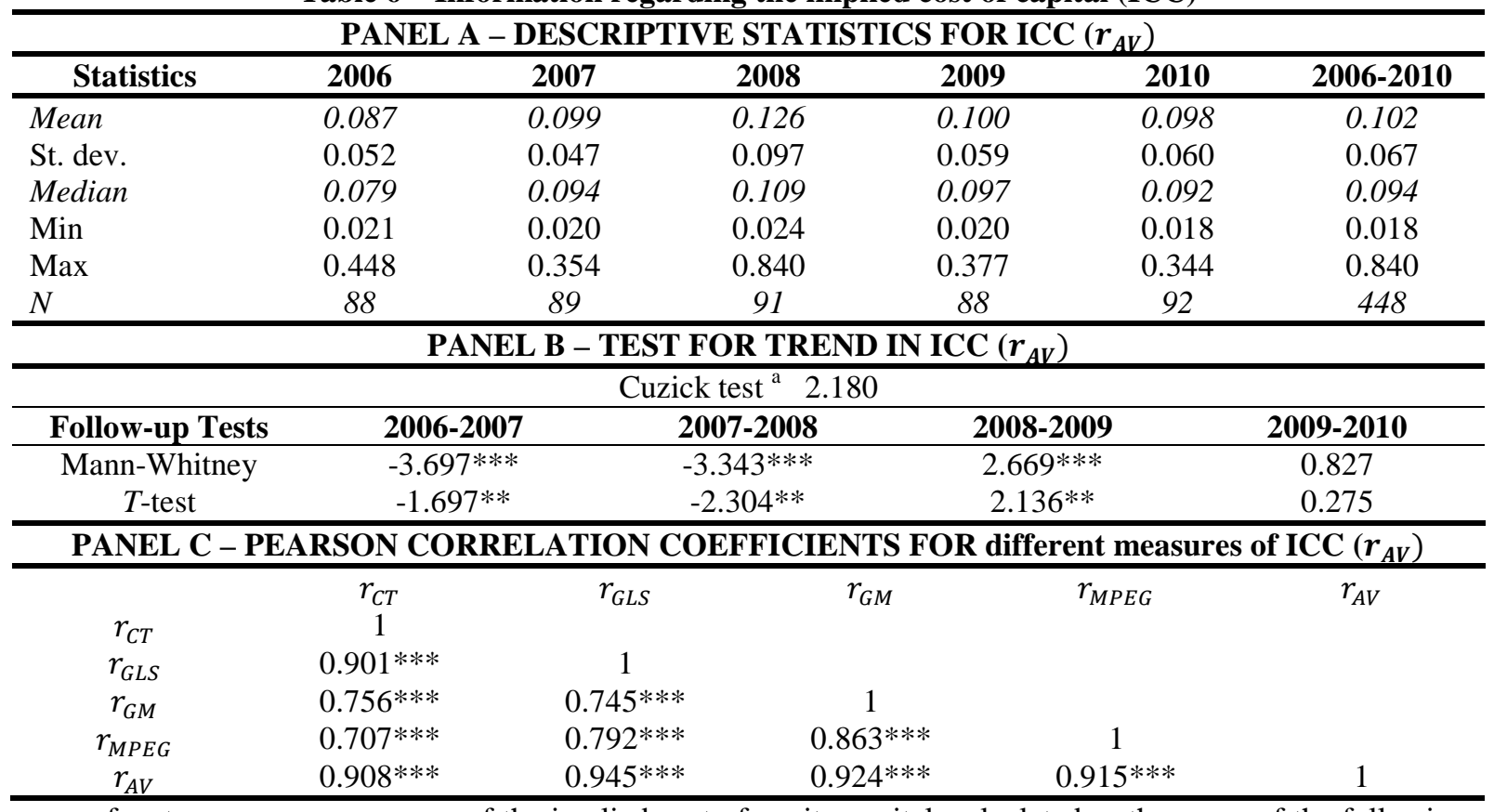

$r_{A V}$ refers to an average measure of the implied cost of equity capital, calculated as the mean of the following measures (c.f., Hail and Leuz, 2006): $r_{C T}$ (Claus and Thomas, 2001), $r_{G L S}$ (Gebhardt et al., 2001), $r_{G M}$ (Gode and Mohanran, 2003), $r_{M P E G}$ (Easton, 2004). See Appendix C for a brief description of each measure.

a The Cuzick (1985) test is a non-parametric test for the trend across ordered groups.

The *,**,*** denote significance at the $10 \%, 5 \%$, and $1 \%$ levels respectively. 
Table 7 - Pearson's correlation coefficients

\begin{tabular}{|c|c|c|c|c|c|c|c|c|c|c|c|}
\hline & $r A V^{\mathrm{a}}$ & $M V^{\mathrm{a}}$ & $\begin{array}{c}\text { OvKPIsRep } \\
\text { rank }\end{array}$ & $\begin{array}{c}\text { FKPIsRep } \\
\text { rank }\end{array}$ & $\begin{array}{c}\text { NonFKPIsRep } \\
\text { rank } \\
\end{array}$ & $\begin{array}{c}\text { OvKPIsRep } \\
\text { norm }\end{array}$ & $\begin{array}{c}\text { FKPIsRep } \\
\text { norm }\end{array}$ & $\begin{array}{c}\text { NonFKPIsRep } \\
\text { norm }\end{array}$ & $\begin{array}{c}\text { OvKPIsSec } \\
\text { rank }\end{array}$ & $\begin{array}{c}\text { FKPIsSec } \\
\text { rank }\end{array}$ & $\begin{array}{c}\text { NonFKPIsSec } \\
\text { rank }\end{array}$ \\
\hline$r A V^{\mathrm{a}}$ & 1 & & & & & & & & & & \\
\hline$M V^{\mathrm{a}}$ & $-0.192 * * *$ & 1 & & & & & & & & & \\
\hline OvKPIsRep_rank & $-0.129 * * *$ & $0.326 * * *$ & 1 & & & & & & & & \\
\hline FKPIsRep_rank & $-0.181 * * *$ & $0.361^{* * *}$ & $0.852 * * *$ & 1 & & & & & & & \\
\hline NonFKPIsRep_rank & -0.025 & $0.168^{* * *}$ & $0.678 * * *$ & $0.427 * * *$ & 1 & & & & & & \\
\hline OvKPIsRep_norm & $-0.121 * * *$ & $0.321^{* * *}$ & $0.981^{* * *}$ & $0.850 * * *$ & $0.680 * * *$ & 1 & & & & & \\
\hline FKPIsRep_norm & $-0.160 * * *$ & $0.354 * * *$ & $0.819 * * *$ & $0.981 * * *$ & $0.426 * * *$ & $0.846 * * *$ & 1 & & & & \\
\hline NonFKPIsRep_norm & -0.038 & $0.159 * * *$ & $0.641^{* * *}$ & $0.412 * * *$ & $0.986 * * *$ & $0.656 * * *$ & $0.419 * * *$ & 1 & & & \\
\hline OvKPIsSec_rank & $-0.151 * * *$ & $0.348^{* * *}$ & $0.940 * * *$ & $0.909 * * *$ & $0.588 * * *$ & $0.927 * * *$ & $0.884 * * *$ & $0.560 * * *$ & 1 & & \\
\hline FKPIsSec_rank & $-0.179 * * *$ & $0.359 * * *$ & $0.853 * * *$ & $0.919 * * *$ & $0.426 * * *$ & $0.850 * * *$ & $0.981 * * *$ & $0.411^{* * *}$ & $0.910 * * *$ & 1 & \\
\hline NonFKPIsSec_rank & -0.040 & $0.154^{* * *}$ & $0.581^{* * *}$ & $0.439 * * *$ & $0.823 * * *$ & $0.582^{* * *}$ & $0.431 * * *$ & $0.825^{* * *}$ & $0.618 * * *$ & $0.438 * * *$ & 1 \\
\hline FKPIsSec_norm & $-0.158 * * *$ & $0.353 * * *$ & $0.820 * * *$ & $0.982 * * *$ & $0.425 * * *$ & $0.846 * * *$ & $0.908 * * *$ & $0.418 * * *$ & $0.885^{* * *}$ & $0.981 * * *$ & $0.430 * * *$ \\
\hline NonFKPIsSec_norm & -0.048 & $0.155^{* * *}$ & $0.534 * * *$ & $0.415 * * *$ & $0.788^{* * *}$ & $0.546^{* * *}$ & $0.411 * * *$ & $0.813^{* * *}$ & $0.576^{* * *}$ & $0.413^{* * *}$ & $0.927 * * *$ \\
\hline$B V^{\mathrm{a}}$ & $-0.171^{* * *}$ & $0.877 * * *$ & $0.317 * * *$ & $0.339 * * *$ & $0.229 * * *$ & $0.311^{* * *}$ & $0.338 * * *$ & $0.223 * * *$ & $0.334 * * *$ & $0.338 * * *$ & $0.241^{* * *}$ \\
\hline$M 2 B^{\mathrm{a}}$ & $-0.134 * * *$ & 0.022 & 0.008 & 0.020 & 0.008 & 0.005 & -0.002 & 0.023 & 0.016 & 0.019 & 0.018 \\
\hline$N I^{\mathrm{a}}$ & $-0.202^{* * *}$ & $0.906^{* * *}$ & $0.305^{* * *}$ & $0.332 * * *$ & $0.155^{* * *}$ & $0.302^{* * *}$ & $0.326^{* * *}$ & $0.149 * * *$ & $0.325^{* * *}$ & $0.330 * * *$ & $0.138^{* * *}$ \\
\hline SalG $^{\mathrm{a}}$ & -0.054 & -0.057 & -0.074 & -0.025 & -0.059 & -0.067 & -0.021 & -0.032 & -0.049 & -0.024 & -0.032 \\
\hline$A W C A^{\mathrm{a}}$ & 0.009 & $-0.113^{* *}$ & -0.052 & -0.026 & -0.003 & -0.033 & -0.016 & 0.015 & -0.027 & -0.028 & 0.046 \\
\hline$r V a r^{a}$ & $0.245^{* * *}$ & $-0.166 * * *$ & $-0.118 * *$ & $-0.091 *$ & $-0.133^{* * *}$ & $-0.112^{* *}$ & $-0.085 *$ & $-0.133^{* * *}$ & $-0.094^{* *}$ & $-0.092 *$ & $-0.097 * *$ \\
\hline Dispersion $^{\mathrm{a}}$ & $0.325^{* * *}$ & 0.052 & 0.047 & 0.016 & 0.025 & 0.025 & 0.002 & 0.015 & 0.026 & 0.017 & 0.030 \\
\hline AnFollow & $-0.186 * * *$ & $0.581^{* * *}$ & $0.281^{* * *}$ & $0.301 * * *$ & $0.237 * * *$ & $0.274 * * *$ & $0.291 * * *$ & $0.234 * * *$ & $0.302 * * *$ & $0.297 * * *$ & $0.249 * * *$ \\
\hline
\end{tabular}

(continued next page) 


\begin{tabular}{|c|c|c|c|c|c|c|c|c|c|c|c|}
\hline & $\begin{array}{c}\text { OvKPIsSec } \\
\text { norm }\end{array}$ & $\begin{array}{c}\text { FKPIsSec } \\
\text { norm }\end{array}$ & $\begin{array}{c}\text { NonFKPIsSec } \\
\text { norm }\end{array}$ & $B V^{\mathrm{a}}$ & $M 2 B^{\mathrm{a}}$ & $N I^{\mathrm{a}}$ & $\operatorname{SalG}^{\mathrm{a}}$ & $A W C A^{\mathrm{a}}$ & $r \operatorname{Var}^{\mathrm{a}}$ & Dispersion $^{\mathrm{a}}$ & AnFollow \\
\hline OvKPIsSec_norm & 1 & & & & & & & & & & \\
\hline FKPIsSec_norm & $0.911^{* * *}$ & 1 & & & & & & & & & \\
\hline NonFKPIsSec_norm & $0.571 * * *$ & $0.412 * * *$ & 1 & & & & & & & & \\
\hline$B V^{\mathrm{a}}$ & $0.334^{* * *}$ & $0.336^{* * *}$ & $0.233^{* * *}$ & 1 & & & & & & & \\
\hline$M 2 B^{\mathrm{a}}$ & 0.012 & -0.003 & 0.030 & $-0.116^{* *}$ & 1 & & & & & & \\
\hline$N I^{\mathrm{a}}$ & $0.326 * * *$ & $0.325^{* * *}$ & $0.132 * * *$ & $0.774^{* * *}$ & 0.025 & 1 & & & & & \\
\hline $\operatorname{SalG}^{\mathrm{a}}$ & -0.041 & -0.021 & -0.006 & -0.039 & 0.028 & -0.024 & 1 & & & & \\
\hline$A W C A^{\mathrm{a}}$ & -0.011 & -0.018 & 0.059 & $-0.113^{* *}$ & $0.165^{* * *}$ & $-0.100 * *$ & $0.127 * * *$ & 1 & & & \\
\hline$r V a r^{a}$ & $-0.086 *$ & $-0.085^{*}$ & $-0.094^{* *}$ & $-0.129 * * *$ & $-0.103^{* *}$ & $-0.146 * * *$ & $0.113^{* *}$ & $0.155^{* * *}$ & 1 & & \\
\hline Dispersion $^{\mathrm{a}}$ & 0.002 & 0.002 & 0.021 & -0.20 & $-0.082 *$ & 0.057 & 0.047 & 0.016 & $0.185^{* * *}$ & 1 & \\
\hline AnFollow & $0.293^{* * *}$ & $0.289 * * *$ & $0.236 * * *$ & $0.520 * * *$ & $0.100 * *$ & $0.548 * * *$ & $-0.130 * * *$ & -0.064 & $-0.189 * * *$ & -0.022 & 1 \\
\hline
\end{tabular}

$r_{A V}$ refers to an average measure of the implied cost of equity capital, calculated as the mean of the following measures (c.f., Hail and Leuz, 2006): $r_{C T}$ (Claus and Thomas, 2001), $r_{G L S}$ (Gebhardt et al., 2001), $r_{G M}$ (Gode and Mohanran, 2003), and $r_{M P E G}$ (Easton, 2004). See Appendix C for a brief description of each measure.

OvKPIs is a measure of the quality of financial and nonfinancial KPIs. Disclosure quality is measured as compliance with the OFR (ASB, 2006). See subsection 3.2 for a detailed description of the measure of KPI disclosure quality. FKPIs and NFinKPIs indicate the quality of financial and nonfinancial KPIs respectively. Suffix Rep means that KPI quality was measured throughout the whole annual report. Suffix Sec means that KPI quality was measured in the Business Review section only. Suffixes rank and norm mean that KPI quality was transformed using percentile ranking and normal scores respectively. For the calculation of these variables see subsection 3.2 .

$M V$ is market value of equity (WC08001); $B V$ is book value of equity (WC03501); $M 2 B$ is the market value to book value of equity (WC08001/WC03501); NI is net income (WC01751); SalG is sales growth computed as (Sales - Sales $_{t-1}$ )/Sales St-1 $_{t}$ (WC01001); AWCA is the absolute value of abnormal working capital accruals scaled by endof-the-year total assets, calculated according to Marra et al. (2011); $r$ Var is the return variance over the financial year computed as $\ln \left(R I_{t_{-11}} / R I_{t_{0}}\right)$; Dispersion is the EPS forecasts standard deviation from IBES (STDEV); and AnFollow is the number of analysts following from IBES (NUMEST).

${ }^{a}$ Variables winsorised at the 2nd and 98th percentiles.

The $*, * *, * * *$ denote significance at the $10 \%, 5 \%$, and $1 \%$ levels respectively. 
Table 8 - Determinants of ICC $\left(r_{A V}\right)$ and KPIs disclosure quality

\begin{tabular}{|c|c|c|c|c|c|c|c|c|}
\hline \multirow[b]{3}{*}{ Constant } & \multicolumn{4}{|c|}{$\begin{array}{c}\text { Quality of KPIs disclosed } \\
\text { in Annual Report }\end{array}$} & \multicolumn{4}{|c|}{$\begin{array}{c}\text { Quality of KPIs disclosed } \\
\text { in KPIs' Section }\end{array}$} \\
\hline & \multicolumn{2}{|c|}{ Overall } & \multicolumn{2}{|c|}{$\begin{array}{l}\text { Financial \& } \\
\text { Nonfinancial }\end{array}$} & \multicolumn{2}{|c|}{ Overall } & \multicolumn{2}{|c|}{$\begin{array}{l}\text { Financial \& } \\
\text { Nonfinancial }\end{array}$} \\
\hline & $\begin{array}{c}0.109 * * * \\
(8.24)\end{array}$ & $\begin{array}{r}0.102^{* * *} \\
(7.58)\end{array}$ & $\begin{array}{r}0.109 * * * \\
(8.03)\end{array}$ & $\begin{array}{r}0.102 * * * \\
(7.35)\end{array}$ & $\begin{array}{r}0.109 * * * \\
(8.05)\end{array}$ & $\begin{array}{r}0.101^{* * *} \\
(7.76)\end{array}$ & $\begin{array}{r}0.110^{* * *} \\
(7.84)\end{array}$ & $\begin{array}{r}0.102^{* * *} \\
(7.18)\end{array}$ \\
\hline OvKPIsRep_rank & $\begin{array}{l}-0.016 \\
(-1.45)\end{array}$ & & & & & & & \\
\hline FKPIsRep_rank & & & $\begin{array}{r}-0.029 * * \\
(-2.53)\end{array}$ & & & & & \\
\hline NonFKPIsRep_rank & & & $\begin{array}{l}0.014 \\
(1.23)\end{array}$ & & & & & \\
\hline OvKPIsRep_norm & & $\begin{array}{r}-0.004 \\
(-1.26)\end{array}$ & & & & & & \\
\hline FKPIsRep_norm & & & & $\begin{array}{r}-0.007 * * \\
(-2.05)\end{array}$ & & & & \\
\hline NonFKPIsRep_norm & & & & $\begin{array}{r}0.003 \\
(0.92)\end{array}$ & & & & \\
\hline OvKPIsSec_rank & & & & & $\begin{array}{l}-0.018 \\
(-1.58)\end{array}$ & & & \\
\hline FKPIsSec_rank & & & & & & & $\begin{array}{r}-0.027 * * \\
(-2.39)\end{array}$ & \\
\hline NonFKPIsSec_rank & & & & & & & $\begin{array}{r}0.011 \\
(0.94)\end{array}$ & \\
\hline OvKPIsSec_norm & & & & & & $\begin{array}{l}-0.004 \\
(-1.41)\end{array}$ & & \\
\hline FKPIsSec_norm & & & & & & & & $\begin{array}{r}-0.006^{*} \\
(-1.92)\end{array}$ \\
\hline NonFKPIsSec_norm & & & & & & & & $\begin{array}{l}0.002 \\
(0.66)\end{array}$ \\
\hline$M 2 B^{\mathrm{a}}$ & $\begin{array}{l}-0.001 \\
(-1.14)\end{array}$ & $\begin{array}{l}-0.001 \\
(-1.14)\end{array}$ & $\begin{array}{r}-0.001 \\
(-1.13)\end{array}$ & $\begin{array}{l}-0.001 \\
(-1.17)\end{array}$ & $\begin{array}{l}-0.001 \\
(-1.15)\end{array}$ & $\begin{array}{l}-0.001 \\
(-1.15)\end{array}$ & $\begin{array}{l}-0.001 \\
(-1.13)\end{array}$ & $\begin{array}{l}-0.001 \\
(-1.17)\end{array}$ \\
\hline $\operatorname{SalG}^{\mathrm{a}}$ & $\begin{array}{l}-0.022 \\
(-1.03)\end{array}$ & $\begin{array}{l}-0.022 \\
(-1.03)\end{array}$ & $\begin{array}{l}-0.020 \\
(-0.95)\end{array}$ & $\begin{array}{l}-0.021 \\
(-0.97)\end{array}$ & $\begin{array}{l}-0.021 \\
(-1.00)\end{array}$ & $\begin{array}{l}-0.021 \\
(-1.00)\end{array}$ & $\begin{array}{l}-0.020 \\
(-0.96)\end{array}$ & $\begin{array}{l}-0.021 \\
(-0.97)\end{array}$ \\
\hline$A W C A^{\mathrm{a}}$ & $\begin{array}{l}-0.011 \\
(-0.14)\end{array}$ & $\begin{array}{l}-0.009 \\
(-0.11)\end{array}$ & $\begin{array}{l}-0.013 \\
(-0.17)\end{array}$ & $\begin{array}{l}-0.011 \\
(-0.14)\end{array}$ & $\begin{array}{l}-0.008 \\
(-0.10)\end{array}$ & $\begin{array}{l}-0.006 \\
(-0.08)\end{array}$ & $\begin{array}{l}-0.017 \\
(-0.22)\end{array}$ & $\begin{array}{l}-0.013 \\
(-0.16)\end{array}$ \\
\hline$r \operatorname{Var}^{\mathrm{a}}$ & $\begin{array}{r}0.750^{* *} \\
(2.29)\end{array}$ & $\begin{array}{r}0.757^{* *} \\
(2.29)\end{array}$ & $\begin{array}{r}0.792 * * \\
(2.51)\end{array}$ & $\begin{array}{r}0.792^{* *} \\
(2.48)\end{array}$ & $\begin{array}{r}0.760 * * \\
(2.32)\end{array}$ & $\begin{array}{r}0.766^{* *} \\
(2.30)\end{array}$ & $\begin{array}{r}0.773^{* *} \\
(2.42)\end{array}$ & $\begin{array}{r}0.776^{* *} \\
(2.39)\end{array}$ \\
\hline Dispersion $^{\text {a }}$ & $\begin{array}{r}0.004^{* * * *} \\
(4.81)\end{array}$ & $\begin{array}{r}0.004^{* * *} \\
(4.77)\end{array}$ & $\begin{array}{r}0.004 * * * \\
(4.74)\end{array}$ & $\begin{array}{r}0.004^{* * *} \\
(4.69)\end{array}$ & $\begin{array}{r}0.004 * * * \\
(4.82)\end{array}$ & $\begin{array}{r}0.004 * * * \\
(4.76)\end{array}$ & $\begin{array}{r}0.004 * * * \\
(4.68)\end{array}$ & $\begin{array}{r}0.004 * * * \\
(4.64)\end{array}$ \\
\hline AnFollow & $\begin{array}{r}-0.001^{*} \\
(-1.79) \\
\end{array}$ & $\begin{array}{r}-0.001^{*} \\
(-1.85) \\
\end{array}$ & $\begin{array}{r}-0.001^{*} \\
(-1.67) \\
\end{array}$ & $\begin{array}{r}-0.001^{*} \\
(-1.74) \\
\end{array}$ & $\begin{array}{r}-0.001^{*} \\
(-1.70) \\
\end{array}$ & $\begin{array}{r}-0.001^{*} \\
(-1.78) \\
\end{array}$ & $\begin{array}{r}-0.001^{*} \\
(-1.69) \\
\end{array}$ & $\begin{array}{r}-0.001^{*} \\
(-1.76) \\
\end{array}$ \\
\hline$N$ & 448 & 448 & 448 & 448 & 448 & 448 & 448 & 448 \\
\hline$F$ & $10.92 * * *$ & $10.69^{* * *}$ & $11.61^{* * *}$ & $10.38^{* * *}$ & $11.00 * * *$ & $10.71^{* * *}$ & $11.49^{* * *}$ & $10.35^{* * *}$ \\
\hline$R^{2}$-adj & 0.174 & 0.172 & 0.188 & 0.180 & 0.177 & 0.174 & 0.185 & 0.178 \\
\hline Max VIF & 1.75 & 1.75 & 1.76 & 1.76 & 1.75 & 1.75 & 1.75 & 1.75 \\
\hline Hausman test $\left(X^{2}\right)^{b}$ & 1.58 & 1.39 & 3.59 & 2.07 & 1.31 & 1.24 & 1.88 & 1.72 \\
\hline
\end{tabular}

$r_{A V}$ refers to an average measure of the implied cost of equity capital, calculated as the mean of the following measures (c.f., Hail and Leuz, 2006): $r_{C T}$ (Claus and Thomas, 2001), $r_{G L S}$ (Gebhardt et al., 2001), $r_{G M}$ (Gode and Mohanran, 2003), $r_{M P E G}$ (Easton, 2004). See Appendix C for a brief description of each measure.

OvKPIs is a measure of the quality of financial and nonfinancial KPIs. Disclosure quality is measured as compliance with OFR best practice guidelines (ASB, 2006). See subsection 3.2 for a detailed description of the measure of KPI disclosure quality. FKPIs and NFinKPIs indicate the quality of financial and non- financial KPIs respectively. Suffix Rep means that the KPI quality was measured throughout the whole annual report. Suffix Sec means that the KPI quality was measured in the Business Review section only. Suffixes rank and norm mean that the KPI quality was transformed using percentile ranking and normal scores respectively. For the calculation of these variables see subsection 3.2.

M2B is the market value to book value of equity (WC08001/WC03501); SalG is sales growth computed as $\left(\right.$ Sale $_{t}-$ Sale $\left._{t-1}\right) /$ Sale $_{t-1}$ (WC01001); AWCA is the absolute value of abnormal working capital accruals scaled by end-of-the-year total assets, calculated according to Marra et al. (2011); rVar is the return variance over the financial year computed as $\ln \left(R I_{t_{-11}} / R I_{t_{0}}\right)$; Dispersion is the EPS forecasts standard deviation from IBES (STDEV); and AnFollow is the number of analysts following from IBES (NUMEST).

${ }^{\text {a }}$ Variables winsorised at the 2nd and 98th percentiles.

${ }^{\mathrm{b}}$ Hausman test is used to compare results from OLS and 2SLS regressions as discussed in Section 3.3.

The *,**, and *** denote significance at the $10 \%, 5 \%$, and $1 \%$ levels respectively. 
Table 9 - Value relevance of accounting information and quality of KPIs disclosure

\begin{tabular}{|c|c|c|c|c|c|c|c|c|}
\hline \multirow[b]{3}{*}{ Constant } & \multicolumn{4}{|c|}{$\begin{array}{c}\text { Quality of KPIs disclosed } \\
\text { in Annual Report }\end{array}$} & \multicolumn{4}{|c|}{$\begin{array}{c}\text { Quality of KPIs disclosed } \\
\text { in KPIs' Section }\end{array}$} \\
\hline & \multicolumn{2}{|c|}{ Overall } & \multicolumn{2}{|c|}{$\begin{array}{c}\text { Financial \& } \\
\text { Nonfinancial }\end{array}$} & \multicolumn{2}{|c|}{ Overall } & \multicolumn{2}{|c|}{$\begin{array}{c}\text { Financial \& } \\
\text { Nonfinancial }\end{array}$} \\
\hline & $\begin{aligned} 0.877^{*} \\
(1.72)\end{aligned}$ & $\begin{array}{r}1.244^{* * *} \\
(3.12)\end{array}$ & $\begin{array}{c}0.747 \\
(1.60)\end{array}$ & $\begin{array}{r}1.327^{* * *} \\
(2.68)\end{array}$ & $\begin{array}{r}0.830 \\
(1.161)\end{array}$ & $\begin{array}{r}1.271^{* * *} \\
(3.24)\end{array}$ & $\begin{array}{r}0.757 \\
(1.61)\end{array}$ & $\begin{array}{r}1.304^{* * *} \\
(2.73)\end{array}$ \\
\hline$B V^{\mathrm{a}}$ & $\begin{array}{r}1.002^{* * *} \\
(3.89)\end{array}$ & $\begin{array}{r}1.002 * * * \\
(3.88)\end{array}$ & $\begin{array}{r}0.999 * * * \\
(3.84)\end{array}$ & $\begin{array}{r}0.996^{* * *} \\
(3.81)\end{array}$ & $\begin{array}{r}0.998^{* * *} \\
(3.90)\end{array}$ & $\begin{array}{r}0.998 * * * \\
(3.89)\end{array}$ & $\begin{array}{r}0.998 * * * \\
(3.89)\end{array}$ & $\begin{array}{r}0.997 * * * \\
(3.86)\end{array}$ \\
\hline$N I^{\mathrm{a}}$ & $\begin{array}{r}8.036 * * * \\
(8.35)\end{array}$ & $\begin{array}{r}8.028 * * * \\
(8.36)\end{array}$ & $\begin{array}{r}7.993 * * * \\
(8.43)\end{array}$ & $\begin{array}{r}8.010 * * * \\
(8.39)\end{array}$ & $\begin{array}{r}8.039 * * * \\
(8.40)\end{array}$ & $\begin{array}{r}8.029 * * * \\
(8.39)\end{array}$ & $\begin{array}{r}7.977^{* * *} \\
(8.51)\end{array}$ & $\begin{array}{r}8.010^{* * * *} \\
(8.46)\end{array}$ \\
\hline OvKPIsRep_rank & $\begin{array}{r}0.696 \\
(0.96)\end{array}$ & & & & & & & \\
\hline FKPIsRep_rank & & & $\begin{array}{r}1.348 * * \\
(2.02)\end{array}$ & & & & & \\
\hline NonFKPIsRep_rank & & & $\begin{array}{l}-0.300 \\
(-0.32)\end{array}$ & & & & & \\
\hline OvKPIsRep_norm & & $\begin{array}{r}0.225 \\
(1.12)\end{array}$ & & & & & & \\
\hline FKPIsRep_norm & & & & $\begin{array}{r}0.320^{*} \\
(1.76)\end{array}$ & & & & \\
\hline NonFKPIsRep_norm & & & & $\begin{array}{l}0.025 \\
(0.09)\end{array}$ & & & & \\
\hline OvKPIsSec_rank & & & & & $\begin{array}{l}0.839 \\
(1.20)\end{array}$ & & & \\
\hline FKPIsSec_rank & & & & & & & $\begin{array}{r}1.349 * \\
(1.93)\end{array}$ & \\
\hline NonFKPIsSec_rank & & & & & & & $\begin{array}{l}-0.388 \\
(-0.41)\end{array}$ & \\
\hline OvKPIsSec_norm & & & & & & $\begin{array}{l}0.268 \\
(1.39)\end{array}$ & & \\
\hline FKPIsSec_norm & & & & & & & & $\begin{array}{r}0.321^{*} \\
(1.68)\end{array}$ \\
\hline & & & & & & & & $\begin{array}{l}-0.005 \\
(-0.02)\end{array}$ \\
\hline$N$ & 448 & 448 & 448 & 448 & 448 & 448 & 448 & 448 \\
\hline$F$ & $205^{* * *}$ & $205^{* * *}$ & $156^{* * *}$ & $155^{* * *}$ & $205^{* * *}$ & $205^{* * *}$ & $157^{* * *}$ & $157^{* * *}$ \\
\hline$R^{2}$-adj & 0.769 & 0.770 & 0.770 & 0.770 & 0.770 & 0.770 & 0.770 & 0.770 \\
\hline Max VIF & 1.98 & 1.97 & 1.98 & 1.98 & 1.98 & 1.98 & 2.00 & 2.00 \\
\hline
\end{tabular}

OvKPIs is a measure of the quality of financial and nonfinancial KPIs. Disclosure quality is measured as compliance with the OFR best practice guidelines (ASB, 2006). See subsection 3.2 for a detailed description of the measure of KPI disclosure quality. FKPIs and NFinKPIs indicate the quality of financial and nonfinancial KPIs respectively. Suffix Rep means that the KPI quality was measured throughout the whole annual report. Suffix Sec means that the KPI quality was measured in the Business Review section only. Suffixes rank and norm mean that the KPI quality was transformed using percentile ranking and normal scores respectively. For the calculation of these variables see subsection 3.2.

$M V$ is market value of equity (WC08001); BV is book value of equity (WC03501); and NI is net income (WC01751).

${ }^{\mathrm{a}}$ Variables winsorised at the 2nd and 98th percentiles

The $*$, **, and *** denote significance at the $10 \%, 5 \%$ s and $1 \%$ levels respectively. 
APPENDIX A: Qualitative characteristics for KPIs disclosure (ASB, 2006)

ASB (2006) (Paragraph 76, page 23):

76. For each KPI disclosed in the OFR:

1) the definition and its calculation method should be explained

2) its purpose should be explained

3) the source of underlying data should be disclosed and, where relevant, assumptions explained

4) quantification or commentary on future targets should be provided

5) where information from the financial statements has been adjusted for inclusion in the OFR, that fact should be highlighted and a reconciliation provided

6) where available, the corresponding amount for the financial year immediately preceding the current year should be disclosed

7) any changes to KPIs should be disclosed and the calculation method used compared to previous financial years, including significant changes in the underlying accounting policies adopted in the financial statements should be identified and explained.

Reflecting on the examples provided by the Reporting Statement (ASB, 2006: pp. 29-38), we capture data related to item four as two different types of information (either quantitative or narrative discussion). This is why eight qualitative characteristics are listed in Table 5. 
Appendix B - Example of measuring quantity and quality of KPIs reporting (Hypothetical firm A)

\begin{tabular}{|c|c|c|c|c|c|c|c|c|c|}
\hline KPI name & $\begin{array}{l}\text { Definition } \\
\text { and } \\
\text { calculation } \\
\text { method }\end{array}$ & $\begin{array}{l}\text { Purpose } \\
\text { for } \\
\text { disclosing }\end{array}$ & $\begin{array}{c}\text { Source of } \\
\text { underlying } \\
\text { data }\end{array}$ & $\begin{array}{c}\text { Quantification } \\
\text { of future } \\
\text { targets }\end{array}$ & $\begin{array}{l}\text { Commentary } \\
\text { on future } \\
\text { targets }\end{array}$ & $\begin{array}{c}\text { Corresponding } \\
\text { amount for the } \\
\text { previous } \\
\text { financial year }\end{array}$ & $\begin{array}{l}\text { Information } \\
\text { from the } \\
\text { financial } \\
\text { statements } \\
\text { has been } \\
\text { adjusted }\end{array}$ & $\begin{array}{l}\text { Changes to } \\
\text { KPIs and } \\
\text { the } \\
\text { calculation } \\
\text { method used } \\
\text { compared to } \\
\text { previous } \\
\text { financial } \\
\text { year }\end{array}$ & $\begin{array}{l}\text { KPI } \\
\text { disclosure } \\
\text { quality } \\
\text { score }\end{array}$ \\
\hline Sales growth & 1 & 1 & 1 & 0 & 0 & 1 & 1 & 0 & 0.625 \\
\hline $2 \quad \begin{array}{c}\text { Underlying volume } \\
\text { growth }\end{array}$ & 1 & 1 & 1 & 0 & 0 & 1 & 1 & 0 & 0.625 \\
\hline Operating margin & 1 & 0 & 0 & 0 & 0 & 1 & 0 & 0 & 0.250 \\
\hline $\begin{array}{c}\text { Ungeared free cash } \\
\text { flow }\end{array}$ & 1 & 1 & 1 & 0 & 0 & 1 & 1 & 0 & 0.625 \\
\hline $\begin{array}{cc}5 & \text { Return on invested } \\
\text { capital }\end{array}$ & 1 & 1 & 1 & 0 & 0 & 1 & 1 & 0 & 0.625 \\
\hline $\begin{array}{cc}6 & \text { Total shareholder } \\
\text { return }\end{array}$ & 1 & 1 & 0 & 0 & 0 & 1 & 0 & 0 & 0.375 \\
\hline $\begin{array}{l}\text { Quantity of Financial } \\
\text { KPIs: } 6\end{array}$ & & & & & & & & Financial & $\begin{array}{r}\text { Quality of } \\
\text { KPIs: } 0.521 \\
\end{array}$ \\
\hline $\begin{array}{cc}1 & \text { Total recordable } \\
\text { accident frequency } \\
\text { rate }\end{array}$ & 1 & 1 & 0 & 0 & 0 & 1 & N/A & 1 & 0.571 \\
\hline $\begin{array}{c}\text { CO2 from energy } \\
\text { per tonne of } \\
\text { production }(\mathrm{kg})\end{array}$ & 1 & 1 & 0 & 1 & 1 & 1 & N/A & 0 & 0.714 \\
\hline $\begin{array}{c}\text { Water per tonne of } \\
\text { production (m3) }\end{array}$ & 1 & 1 & 0 & 0 & 0 & 1 & N/A & 0 & 0.429 \\
\hline $\begin{array}{cc}4 & \text { Total waste per } \\
\text { tonne of production }\end{array}$ & 1 & 1 & 0 & 0 & 0 & 1 & N/A & 0 & 0.429 \\
\hline $\begin{array}{l}\text { Quantity of } \\
\text { Non-Financial KPIs: } 4\end{array}$ & & & & & & & & Non- Financial & $\begin{array}{r}\text { Quality of } \\
\text { KPIs: } 0.536\end{array}$ \\
\hline $\begin{array}{l}\text { Overall } \\
\text { KPIs quantity: } 10 \\
\end{array}$ & & & & & & & & \multicolumn{2}{|c|}{$\begin{array}{r}\text { Overall } \\
\text { KPIs quality:0.527 }\end{array}$} \\
\hline
\end{tabular}

